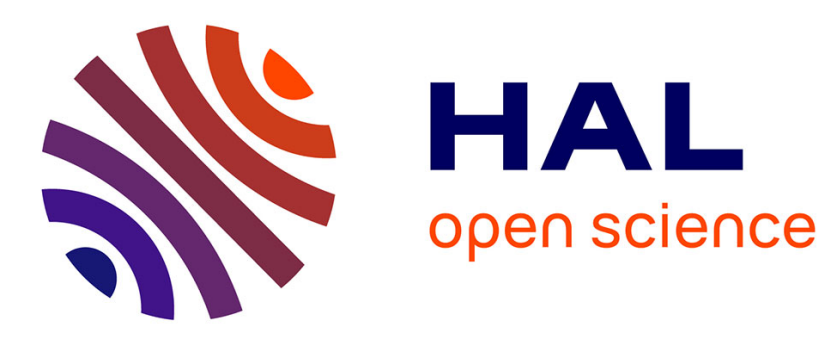

\title{
Weakening of the Senegalo-Mauritanian Upwelling System under climate change
}

Adama Sylla, Juliette Mignot, Xavier Capet, Amadou Thierno Gaye

\section{To cite this version:}

Adama Sylla, Juliette Mignot, Xavier Capet, Amadou Thierno Gaye. Weakening of the SenegaloMauritanian Upwelling System under climate change. Climate Dynamics, 2019, 53 (7-8), pp.44474473. 10.1007/s00382-019-04797-y . hal-02344499

\section{HAL Id: hal-02344499 https://hal.sorbonne-universite.fr/hal-02344499}

Submitted on 4 Nov 2019

HAL is a multi-disciplinary open access archive for the deposit and dissemination of scientific research documents, whether they are published or not. The documents may come from teaching and research institutions in France or abroad, or from public or private research centers.
L'archive ouverte pluridisciplinaire HAL, est destinée au dépôt et à la diffusion de documents scientifiques de niveau recherche, publiés ou non, émanant des établissements d'enseignement et de recherche français ou étrangers, des laboratoires publics ou privés. 


\section{under climate change}

$4 \quad{ }^{1}$ Laboratoire de Physique de l'Atmosphére et de l'Ocean Simeon Fongang (LPAO-SF/ESP/UCAD), Dakar, Sénégal

$5 \quad{ }^{2}$ Sorbonne Universités (CNRS/IRD/MNHN), LOCEAN laboratory, Paris, France

6 Phone: +33144273304

$7 \quad$ Email address: adama.sylla@locean-ipsl.upmc.fr 


\title{
Abstract
}

11 Upwelling processes bring nutrient-rich waters from the deep ocean to the surface. Areas of upwelling are often associated with high productivity, offering great economic value in terms of fisheries. The sensitivity of spring/summer-time coastal upwelling systems to climate change has recently received a lot of attention. Several studies have suggested that their intensity may increase

Keywords: upwelling, climate change, climate models, Northeastern Tropical

\author{
Atlantic
}




\section{Introduction}

The upwelling is an upward motion of sea water from intermediate depths (typically $50-200 \mathrm{~m}$ ) toward the ocean surface. It is an oceanographic phenomenon resulting from the friction of the wind on the ocean surface. Upwelled water masses are colder and richer in nutrients than the surface waters they replace. Upwellings therefore correspond to areas of very productive marine ecosystems and high fish resources. When the upwelling occurs along the coast, thus near fishermen and societies, their economic importance is very high (Gómez-Gesteira et al. 2008) . There are four major coastal upwelling systems (hereafter EBUSs for Eastern Boundary Upwelling Systems) in the global ocean, that are the Canary, Benguela, Humboldt and California systems. These areas cover less than $1 \%$ of the global ocean surface, but they contribute to about $8 \%$ of the global marine primary production and more than $20 \%$ of the global fish catches (Pauly and Christensen 1995) . EBUSs are situated in the tropics and subtropics. There, the trade winds blowing equator-ward parallel to the eastern borders of the ocean basins induce an Ekman transport from the coast to the open ocean, perpendicular to the wind stress forcing. This creates a transport divergence and thereby leads to an upwelling at the coast. This mechanism has been long considered as the main phenomenon that drive the upwelling systems on Earth (Sverdrup 1938). Yet, a divergent oceanic circulation may also be created at the surface by a cyclonic wind stress curl. In the eastern subtropical basins, the tendency for trade winds to slow down near the coast, the so-called wind drop-off (e.g. Bakun and Nelson 1991; Pickett 2003) induces a positive wind stress curl that also contributes to upwelling. The upwelling contributions of coastal Ekman divergence and Ekman pumping are difficult to compare. The former effect is strongly localized nearshore while the latter is more broadly distributed. Their relative importance thus depends on the choice of an across-shore length scale for how far offshore Ekman pumping is being considered that is often largely arbitrary 
and studies do not agree yet (Nelson 1976; Halpern 2002; Pickett 2003; Bravo et al. 2016; Torres 2003; Capet et al. 2004).

Among the four EBUSs mentioned above, we concentrate here on the southern part of the so-called Canary Upwelling System (CUS). This upwelling extends from the coast of West Africa at $\sim 10^{\circ} \mathrm{N}$ to that of the Iberian peninsula around $45^{\circ} \mathrm{N}$ (Aristegui et al. 2005). A comparison of the four major EBUSs shows that the northwest African coast is the most spatially and seasonally variable one in terms of primary production (Carr and Kearns 2003). This variability is still insufficiently documented and understood despite a number of recent studies including (Mason et al. 2011; Ndoye et al. 2014; Benazzouz et al. 2014; Faye et al. 2015). Based on arguments of seasonality, Arístegui et al. (2009) proposed that this system could be divided into 5 sub-regions. In the north, the Galician coast $\left(42^{\circ} \mathrm{N}-45^{\circ} \mathrm{N}\right)$ and the Portuguese coast $\left(37^{\circ} \mathrm{N}-42^{\circ} \mathrm{N}\right)$ are both characterized by a summer-time upwelling when the wind stress forcing reaches its maximum intensity. Further south, in the region of the Gulf of Cadiz $\left(33^{\circ} \mathrm{N}-37^{\circ} \mathrm{N}\right)$ and the Moroccan coast $\left(21^{\circ} \mathrm{N}-33^{\circ} \mathrm{N}\right)$ upwelling presents a reduced seasonality and is accompanied by the southward branch of the subtropical gyre, namely the offshore Canary current. At the southern end of the CUS the strength and position of the wind is highly influenced by the latitudinal migration of the Intertropical Convergence Zone (ITCZ) and the associated Azores high pressure area, both oscillating between their northernmost and southernmost positions in summer and winter respectively (Fig.1). This oscillation of pressure systems generates seasonal wind and SST fluctuations (Mittelstaedt 1991; Nykjær and Van Camp 1994). In winter, the ITCZ reaches its southernmost position between the geographic equator and $5^{\circ} \mathrm{S}$ thereby favoring strong northeastern trade winds along the coast of Guinea, Senegal and Mauritania $\left(12^{\circ} \mathrm{N}-20^{\circ} \mathrm{N}\right)$ and thus the upwelling. This is largely responsible for the cold surface waters seen along the coast in Fig. 1. In summer, when the ITCZ reaches its northernmost position (around $15^{\circ} \mathrm{N}$ ), the winds in this region 
are weak, and even reverse to south westerlies in the southernmost part of the region. In this season, the upwelling is absent along the coast of Senegal and much reduced offshore of Mauritania. In Senegal, this season is also marked by heavy monsoon rainfalls. The Senegalo-Mauritanian Upwelling System (SMUS) has thus a very specific seasonal behavior as compared to the northern part of CUS. This region is the most productive of the five sub-regions. It is the focus of our study.

In 1990, Bakun suggested that an increase of the greenhouse gases concentration in the atmosphere would lead to an intensification of upwelling winds in EBUSs. Given the strong linkages between upwelling and marine ecosystems (Blanchette et al. 2008; Fenberg et al. 2015), such evolution may have very important ecological implications. Precisely, Bakun (1990) hypothesized that inhibition of nighttime cooling and enhancement of daytime heating on land as a result of global warming would lead to the intensification of the continental thermal lows adjacent to upwelling regions. This intensification should lead to increased onshore-offshore atmospheric pressure gradients, accelerated alongshore winds, and thus intensified coastal upwelling circulation. This generic mechanism could in principle be applied to any of the coastal upwelling systems. In the CUS, several analyses have tested this hypothesis. Paleoclimatic reconstructions in the coastal upwelling area off Cape Ghir $\left(30.5^{\circ} \mathrm{N}\right)$ have indeed shown a significant cooling of surface waters around the end of the $20^{\text {th }}$ century, which may reflect an increase of the upwelling intensity (McGregor et al. 2007). Examining the variation of the northern part (near $30.5^{\circ} \mathrm{N}$ ) of the CUS using SST observations datasets and meridional wind observations and reanalysis, Narayan et al. (2010) also concluded that the coastal upwelling intensity has been increasing over the second half of the $20^{\text {th }}$ century (1960-2001). However other studies are at odds with Bakun (1990)'s conceptual view. In particular, Gómez-Gesteira et al. (2008) noted a long-term decrease of the CUS upwelling intensity between $20^{\circ} \mathrm{N}-32^{\circ} \mathrm{N}$ from $1967-2006$ using the AVHRR SST and NOAA time series of zonal Ekman transport. Using reanalysis data sets, Pardo et al. (2011) and Santos et al. 
(2012) have reached similar conclusions for the region spanning from the Iberian coast to Morocco. Finally, using different wind datasets and reanalyses, Barton et al. (2013) have found no statistically significant change of the annual mean wind intensity off Northwest Africa over the second half of the $20^{\text {th }}$ century. Using a NCEP/NCAR reanalysis data for 60 years (Sydeman et al. 2014) found that summertime winds have intensified in the California, Benguela, and Humboldt upwelling systems and weakened in the Iberian system and this mentioned this change is equivocal in the Canary system.

The robustness of these previous results is most of the time limited by the lack of sufficiently long and continuous series of observations. In this context and despite their imperfect representation of fine oceanic structures, climate models provide an interesting alternative to explore the consequences of climate change on coastal upwellings. Mote and Mantua (2002) have used simulations of the $20^{\text {th }}$ and $21^{\text {st }}$ century (1990-2080) based on the NCAR-CSM (Boville and Gent 1998) and the HadCM3 (Gordon et al. 2000) climate models to compute upwelling indices for the four EBUSs including the CUS (over the latitude range $13^{\circ} \mathrm{N}-30^{\circ} \mathrm{N}$ ). They did not find any significant change in the summer upwelling intensity and phasing of the seasonal cycle. More recently, Wang et al. (2015) have analyzed historical and future simulations of 22 CMIP5 Earth system models over the period 1950-2099. Focusing again on the summer season and the offshore wind-driven Ekman transport, they found that the CMIP5 models exhibit a strengthening of the upwelling intensity in the poleward sectors of all EBUSs except the California current system. On the other hand, they found a weakening of the summertime upwelling intensity at lower latitudes, that is between $\sim 15^{\circ} \mathrm{N}$ and $25^{\circ} \mathrm{N}$ for the CUS. A distinction between the northern and southern parts of the CUS was also made in Cropper et al. (2014) for the recent period based on atmospheric reanalyses and in the meta-analysis of Sydeman et al. (2014). According to Wang et al. (2015) and as opposed to Bakun 's hypothesis, an increase in the land-sea thermal difference in this region in 
summer is expected to strengthen the southwesterly monsoon circulation that drives downwellingfavourable winds in the subtropics. All these studies only relate to the summer season, when there is little upwelling along the senegalo-mauritanian coast.

To our knowledge, the future of the SMUS has not been investigated for the cold upwelling season, in spite of its primary importance to the functioning of the ecosystem (Zeeberg et al. 2008; Arístegui et al. 2009). In this paper, we study this system and its future, using climate models. In spite of their rather coarse resolution and biases in the tropical North Atlantic (Richter and Xie 2008; Wahl et al. 2011; Richter et al. 2014) such simulations (presented in section 2) are the only available tool to investigate the upwelling's future. We will define a number of indices to characterize the intensity of upwelling process and its thermal signature in such large scale models, and we will investigate the representation of these indices in the different simulations under presentday conditions. This approach will allow us to propose a first comparison of the different models assessing their ability to represent west African upwelling dynamics and its signature on SST (section 3). The response of upwelling indices to global warming is analyzed in section 4 . Discussion and conclusion are offered in sections 5 and 6 respectively.

\section{Data}

\subsection{Model data}

This study is based on the CMIP5 (Coupled Model Inter-comparison Project Phase 5) data base. This database has already been extensively used for oceanic and climatic studies in the eastern tropical North Atlantic. Several authors have highlighted the general warm SST bias in this region (Breugem et al. 2008; Richter and Xie, 2008; Grodsky et al. 2012; Wahl et al. 2011) potentially due to a surface wind bias during spring (March-May) season (Chang et al. 2007; DeWitt, 2005; Richter et al. 2012) and the poor-representation of low levels clouds (Huang et al. 2007). In order to investigate how the seasonality and intensity of SMUS may change in the future, we have compared 
the output of historical simulations with simulations of the $21^{\text {st }}$ century for the RCP8.5 scenario. The monthly sea surface temperature is available, for the historical period in 47 simulations (Table 1). In terms of oceanic variables, we have also used the sea surface height above geoid, the upward ocean mass transport, the upper-ocean mixed layer depth and the atmospheric wind stress seen by the ocean. When the latter was not available, we have used the atmospheric surface wind velocity instead, which we converted offline into a wind stress following the procedure described below. Regarding atmospheric variables, we have also used the sea level pressure and the precipitation rate. Variables availability is indicated in Table 1 for each climate model that has been retained. The reader is referred to the CMIP5 data base for more information on each of these models. For each variable, we have constructed the average seasonal cycle over the period [1985-2005] (hereafter "present") and the period [2080-2100] (hereafter "future") from the historical (Taylor et al. 2012) and the RCP8.5 (Riahi et al. 2011) simulations respectively. When several ensemble members are available, we only selected the first one, in order to assign the same weight to all the models. To facilitate the analyses, all outputs have subsequently been interpolated over a regular $1^{\circ}$ grid using a bilinear interpolation method as in Rykaczewski et al. (2015).

Some model (BCCBCC-CSM1-1, BCC-CSM1-1-m, HadCM3, HadGEM2-CC, HadGEM2-ES, GISS-E2-H-CC, GISS-E2-R-CC, GISS-E2-H, GISS-E2-R) only provide near-surface winds, and not the wind stress at the air-sea interface. The relationship between the wind speed and the wind stress is usually written as a bulk formula under the form

$$
\tau_{x}=\rho_{a} C_{d}\left(u a s^{2}+v a s^{2}\right)^{1 / 2} \text { uas and } \tau_{y}=\rho_{a} C_{d}\left(u_{a s^{2}}+v_{a s}^{2}\right)^{1 / 2} \text { vas }(1)
$$

with uas and vas the zonal and meridional wind components respectively, $C_{d}$ the drag coefficient and $\rho_{a}$ the air density $\left(\rho_{a}=1.22 \mathrm{~kg} \cdot \mathrm{m}^{-3}\right)$. For the simulations listed above, the wind stress was computed using Eq. (1) and $C_{d}=0.0014$ following Santos et al. (2012) (see appendix A for more details). In these cases, the derived wind stress is used in both the historical and future simulations 
to minimize biases coming from this offline computation. For all the other models, the oceanic wind stress provided in the data base is used. Note that CanCM4 and LASG-CESS models provide neither the wind stress nor the near-surface wind, even over the historical period. All missing data are marked with a dark blue band over Fig. $(4,5,6)$ and a missing bar in Fig. $(7,8,9,10)$. Note also that not all models provide the oceanic mixed layer depth (see table 1). Given the potentially critical dependency of our results on estimations of the MLD, we only show computations involving this variable for models which provide it directly in the database. In other words, we do not attempt to recompute any mixed layer depth.

The Multi-Model Mean (MMM) is also systematically given for each index over both the historical and future period. The number of models incorporated in the calculation of a given MMM index varies according to availability of the input variables for that index, which can differ for present and future. When relevant, the significance of the sign of the MMM is tested statistically according to the number of available models and their spread ( $\mathrm{t}$-test of the mean considering that each model is independent). The significance of the changes in the future is also tested using a t-test that considers each available model as independent. Each significance is given at the $95 \%$ confidence level.

The analyses presented below frequently considers two sub-domains of the SMUS: a northern subdomain between $16^{\circ} \mathrm{N}$ and $20^{\circ} \mathrm{N}$ (hereafter nSMUS for "northern part of SMUS") and a southern subdomain between $12^{\circ} \mathrm{N}$ and $15^{\circ} \mathrm{N}$ (hereafter sSMUS for "southern part of SMUS"). $15^{\circ} \mathrm{N}$ is the latitude of Cape Verde. The latter is a well-known geomorphological irregularity with known dynamical implications in the ocean (Roy 1998; Alpers et al. 2013; Ndoye et al. 2014) and (Kounta et al. 2018). This separation nevertheless arose naturally from our analyses for reasons that will become progressively apparent to the reader. In particular, we find that the late $20^{\text {st }}$ century upwelling projections differ for the two sub-domains.

2.2: Validation data sets 
In order to evaluate the model outputs over the historical period, we have used several observation and reanalysis data sets. As for the climate models outputs, all the validation datasets have been interpolated on a regular $1^{\circ}$ grid, when not originally provided on this grid. Except otherwise specified (Quikscat and AVISO data sets, see below), we use monthly climatologies built over the 1985-2005 time period, i.e., consistent with the period defining present conditions in the climate simulations.

We have used the Extended Reconstructed Sea Surface Temperature data set (ERSST- v3b, Smith and Reynolds 2003) produced by NOAA at $2^{\circ}$ spatial resolution. In order to account for uncertainty on SST observations, we have also used the gridded SST data set from the Met Office Hadley CentreHadISST (Rayner 2003). This data is provided on a $1^{\circ}$ latitude-longitude grid from 1870 to present.

To evaluate the model wind stresses, we have used the $0.25^{\circ}$ resolution Quikscat wind stress climatology for the period 2000-2009 extracted from the https://podaac.jpl.nasa.gov database. The period 2000-2009 is approximately that of the satellite mission. It does not exactly match the "present" period considered in the climate models and this adds a slight uncertainty in the comparison with the climate models outputs. However, the inter-models differences shown below are larger than possible differences between the 1985-2005 and 2000-2009 wind stress climatologies. These direct observations have been compared to the TropFlux reanalysis. This data set combines the ERA-Interim reanalysis for turbulent and long-wave fluxes, and ISCCP (International Satellite Cloud Climatology Project) surface radiation data for shortwave fluxes. This wind stress product is described and evaluated in Praveen Kumar et al. (2013).

Meridional sea surface height (SSH) gradients play an important dynamical role in the SMUS as in other coastal regions (see Sec.3.3). To evaluate the models representation of SSH along the coast, we use the AVISO satellite altimetry product (www.aviso.altimetry.fr; Ducet et al. 2000). 
This data covers the period $1993-2013$ at $0.25^{\circ}$ spatial resolution. For comparison, we have also used the GODAS monthly SSH (https://www.esrl.noaa.gov/psd/gridded/data.godas.html), a monthly reanalysis provided at $0.333^{\circ}$ latitude $x 1^{\circ}$ longitude of resolution. Again these two data sets are averaged over the period [1993-2005] and interpolated over a $1^{\circ}$ longitude-latitude regular grid. Quantifying the effect of the SSH gradient on the geostrophic transport requires an estimation of the oceanic mixed layer depth (MLD). We use the climatology from de Boyer Montégut et al. (2004) available at the spatial resolution of $2^{\circ}$.

To analyse the influence of the large scale atmospheric circulation on the senegalo-mauritanian upwelling over the recent period, we have used sea level pressure fields from ERAI, originally available at $0.75^{\circ} \times 0.75^{\circ}$ resolution (Dee et al. 2011). We have also used the monthly precipitation observations of the Global Precipitation Climatology Project available at https://www.ersl.noaa.gov/psd/data/gridded/data.gpcp.html. The GPCP data cover the period 1979 to 2017 at $2.5^{\circ}$ resolution. These two fields are used to determine the mean latitudinal position of the ITCZ and the Azores Anticyclone (AA) during the upwelling season. The former corresponds to the average latitude of the precipitation maximum between November and May and between $15^{\circ} \mathrm{W}$ and $30^{\circ} \mathrm{W}$. The latter corresponds to the average latitude of the SLP maximum between November and May and between $15^{\circ} \mathrm{W}$ and $30^{\circ} \mathrm{W}$.

\section{Characterization of the upwelling in climate models over the historical} period

Our main objective is to determine the upwelling trends due to climate change in the SMUS. A prerequisite is to define indices that quantify upwelling intensity (and its changes over time) in the climate simulations despite the inability of the models to represent the fine-scale underlying process with realism, at least nearshore. In this section we propose a series of five indices, with varied complexity. Such an approach based on simple indices computed for CMIP5 simulations has been 
applied successfully for example by Bellenger et al. (2014) in the context of ENSO. Note that in the following, brackets $<>$ denote a spatial average of the corresponding index, either along the longitude and/or the latitude. $<>n$ and $<>s$ correspond to spatial averages over the northern and southern SMUS sectors (nSMUS and sSMUS) delimited by the latitudes bands $16-20^{\circ} \mathrm{N}$ and 12 $15^{\circ} \mathrm{N}$ respectively.

\subsection{SST based characterization of upwelling}

\section{1.a Amplitude of seasonal cycle $\left(U I_{\text {sst }}^{\text {seas }}\right)$}

The annual cycle is generally the dominant timescale of temperature variability. In the tropics, however, seasons are less marked than at mid to high latitudes, and variability at this time scale is thus less energetic (e.g. Wang et al. 2015). As explained above, the SMUS is subjected to wintertime coastal cooling and it is therefore a subregional exception regarding seasonality. This feature is illustrated in Fig.2, which shows the amplitude of the SST seasonal cycle averaged zonally between $16^{\circ} \mathrm{W}$ and $20^{\circ} \mathrm{W}$ (noted $\left\langle U U_{\text {sst }}^{\text {seas }}\right\rangle$ ) for both SST data sets (first two columns), each individual simulations, as well as for the multi model mean of CMIP5 historical simulations (last column). The magnitude of the seasonal cycle is maximum between $12^{\circ} \mathrm{N}$ to $20^{\circ} \mathrm{N}$ in the two validation datasets because the seasonal upwelling contributes to wintertime cooling. This latitudinal range stands out between the northern sector (north of $20^{\circ} \mathrm{N}$ ), where summer-time upwelling dominates and tends to compensate the effect of the solar flux seasonal cycle, and the southern sector (south of $12^{\circ} \mathrm{N}$ ) where upwelling is very weak or absent.

The individual simulations generally reproduce an intensified $\left\langle U I_{\text {sst }}^{\text {seas }}\right\rangle$ in the SMUS latitude band, but the maximum intensity and exact latitudinal position differ. The amplitude of $\left\langle U I_{s s t}^{\text {seas }}\right\rangle$ in the models ranges from roughly $3^{\circ} \mathrm{C}$ (IPSL-CM5B-LR) to more than $8^{\circ} \mathrm{C}$ (GFDL models). In 
several models (BCC models, CSIRO-QCCCE, CSIRO-BOM, CMCC-CESM, CCSM4, ECEARTH, LASG-IAP, LASG-CESS, MRI family, MIROC5, NorESM1 group) $\left\langle U I_{\text {sst }}^{\text {seas }}\right\rangle$ is amplified only in the nSMUS and this feature affects the MMM. Conversely, marked seasonalities even extend north of $20^{\circ} \mathrm{N}$ in the FIO-ESM, the GFDL family and MIROC-ESM.

Only a few models appear to have $\left\langle U I_{s s t}^{\text {seas }}\right\rangle$ with realistic amplitude in the correct latitudinal band $\left(12^{\circ} \mathrm{N}-20^{\circ} \mathrm{N}\right.$ roughly). With respect to this criterion, the most realistic models appear to be CCCma, CMCC-CM, CMCC-CMS, CNRM, the HadGEM2 family and LASG-IAP. The CMIP5 Multi Model Mean (MMM) exhibits a realistic magnitude of the SST seasonal cycle, with a maximum of $5^{\circ} \mathrm{C}$ to $6.5^{\circ} \mathrm{C}$ around $15^{\circ} \mathrm{N}$. This is slightly weaker than observed, and this weakness is more pronounced in the sSMUS.

\section{1.b: SST Upwelling Index $\left(U I_{\text {sst }}^{\text {cross }}\right)$}

The difference of SST between the coast and the offshore ocean has been widely used to characterize upwelling intensity (e.g., Speth 1978; Mittelstaedt 1991; Santos et al. 2005; GómezGesteira et al. 2008; Lathuilière et al. 2008; Marcello et al. 2011; Benazzouz et al. 2014). It is generally referred to as the SST Upwelling Index and abbreviated here as $U I_{s s t}^{\text {cross }}$. Gómez-Gesteira et al. (2008) argue that $U I_{\text {sst }}^{\text {cross }}$ lacks robustness because it is sensitive to a variety of processes and in particular the intensity of heat fluxes warming upwelling waters as they reach the surface. Remote modes of climate variability such as ENSO can also result in $U I_{\text {sst }}^{\text {cross }}$ changes that are not related to coastal upwelling dynamics. Despite these caveats, $U I_{s s t}^{\text {cross }}$ is useful to measure the impact of upwelling on the SST zonal structure and to characterize the temporal variability of the system. For each latitude, we define the coastal SST $\left(S S T_{\text {coast }}\right)$, as the SST at the ocean grid box closest to the coast (black points in Fig.1). The offshore SST $\left(S S T_{\text {ocean }}\right)$ is the SST of the grid box located $5^{\circ}$ away from the coast at the same latitude (magenta points in Fig.1). $U I_{s s t}^{\text {cross }}$ is then defined as: 
Upwelling conditions thus correspond to positive values of this index. The $5^{\circ}$ spacing between the coastal and offshore SST has been chosen following previous studies (eg. Cropper et al. 2014). Spacings of $7^{\circ}$ or $9^{\circ}$ have also been tested with no significant differences in the results (not shown).

Fig.3 (first two columns) shows the seasonal evolution of $U I_{s s t}^{\text {cross }}$ averaged in latitude bands over the nSMUS (noted $\left.\left\langle U I_{s s t}^{\text {cross }}\right\rangle_{n}\right)$ and the sSMUS $\left(\left\langle U I_{s s t}^{\text {cross }}\right\rangle_{s}\right)$ over one climatological year in the two observation data sets. The general patterns are similar for the two datasets and consistent with previous studies (Nykjær and Van Camp 1994; Lathuilière et al. 2008; Santos et al. 2012). In the nSMUS (Fig.3.a), the coastal upwelling is marked by positive winter values from November to June well apparent in both data sets (first two columns). In this latitude band, roughly two-third of the models exhibit a change of sign between summer and winter, with a consistent positive $\left\langle U I_{s s t}^{\text {cross }}\right\rangle_{n}$ in winter. On the contrary, some models (CanCM4, CanESM2, CMCC-CM, CMCCCMS, HadGEM2-CC, HadGEM2-ES, HadGEM2-AO and IPSL-CM5A-LR) show positive values all year long, albeit for most of them with relatively weak values in summer indicating that the latitude band of permanent upwelling is displaced to the south compared to observations (where it is restricted to the north of Cape Blanc, $20^{\circ} \mathrm{N}$ ). In spite of these differences, the multi-model mean (MMM) is remarkably consistent with the observations. It is significantly different from zero at the $95 \%$ of confidence level from November to May according to the student test with respect to the model configurations spread.

In the sSMUS (Fig.3b), the positive values of the $\left\langle U I_{s s t}^{\text {cross }}\right\rangle_{s}$ are only observed from December to May in both data sets. The models perform poorly in this latitudinal range. The multi-model mean is negative all year round, albeit with very weak values in winter, and only significantly different from zero during summer again as a consequence of the spread of the models behaviors. 
314 The models tend to show either year-long negative $\left\langle U I_{s s t}^{\text {cross }}\right\rangle_{s}$ (no surface signature of the upwelling, 315 CESM group, FIO-ESM GFDL, GISS), a year long positive $\left\langle U I_{\text {sst }}^{\text {cross }}\right\rangle_{s}$ (permanent signature of the 316 upwelling CNRM, LASG, NorESM1 families), or even a seasonality with the reversed sign (MPI 317 family). The HadGEM2-CC, HadGEM2-ES and HadGEM2-AO simulations stand out as the only 318 ones with a correct seasonality, yet with some deficiencies in terms of phasing and amplitude.

319 To conclude, $\left\langle U I_{\text {sst }}^{\text {cross }}\right\rangle$ appears as a challenging indicator of the surface thermal signature of the 320 upwelling intensity. Specifically, the models fail to reproduce its seasonality in the southernmost 321 region of SMUS, probably due to a bias of the ITCZ position. The origin of this bias is further 322 explored below, in relation to the seasonality of the wind intensity and direction along the west 323 African coast. The diffuse nature of coastal upwelling in low-resolution models is also probably a 324 source of difficulty (see Discussion section 5).

$325 \quad 3.2$ Wind-based characterization of upwelling

326 3.2.a: Contribution for the Ekman transport coastal divergence $\left(U I_{\text {wind }}^{\text {div }}\right)$

327 Assuming that the senegalo-mauritanian coast is orientated meridionally, which is nearly true in the 328 climate models, the Ekman transport can be quantified as:

$$
U I_{\text {wind }}^{\text {div }}=\frac{y}{{ }_{w} f}
$$

330 where $\tau_{y}$ is the meridional wind stress component at the grid box closest to shore, $\rho_{w}$ the sea water 331 density, and $f$ is the Coriolis parameter. $\rho_{w}$ is chosen equal to $1025 \mathrm{~kg} \cdot \mathrm{m}^{-3}$ for our region of interest. $332 U I_{\text {wind }}^{\text {div }}$ is expressed in $\mathrm{m}^{2} \cdot \mathrm{s}^{-1}$ and upwelling conditions correspond to positive $U I_{\text {wind }}^{d i v}$.

Fig.4 shows the climatological cycle of $U I_{\text {wind }}^{d i v}$ averaged over the nSMUS $\left(\left\langle U I_{\text {wind }}^{d i v}\right\rangle_{n}\right)$ and $\operatorname{sSMUS}\left(\left\langle U I_{\text {wind }}^{d i v}\right\rangle_{s}\right)$ for the validation data sets, each model configuration, and the multi-model 
mean. The seasonality of $\left\langle U I_{\text {wind }}^{d i v}\right\rangle_{n}$ (Fig.4a) is modest: the wind index shows a seasonal reduction in summer, but without any change of sign. It nevertheless reaches such weak values that upwelling dynamics may become secondary for the SST budget, hence a plausible reason for the absence of upwelling signature on coastal SSTs as seen above. Most models appropriately capture this characteristic, albeit with a tendency to overestimation. A notable exception is the GFDL family for cycle that is more strongly marked in nSMUS than in the other ones and the data. These models were also characterized by a systematic northward shift of the SST seasonal cycle pattern $\left(\left\langle U I_{s s t}^{\text {seas }}\right\rangle\right.$, Fig.2). As for the MMM, it is very close to the observations and it is significant at the $95 \%$ level for all months of the year.

The seasonal cycle of $\left\langle U I_{\text {wind }}^{d i v}\right\rangle_{s}$ (Fig.4.b) is more clearly marked than the one of $\left\langle U I_{\text {wind }}^{d i v}\right\rangle_{n}$ in the data, and this is well reproduced in the models. Interestingly, in the southern sector the wind remains upwelling-favorable from October to June but the signature of the upwelling on observed SSTs $\left(\left\langle U I_{\text {wind }}^{d i v}\right\rangle_{s}\right)$ is restricted to the period December-May. This one-month lag between the cycle of the upwelling driver and that of its SST signature has been noted before (e.g., Nykjær and Van Camp 1994; Cropper et al. 2014). A plausible explanation is that the overall weakness of the winds at the beginning and end of the season makes upwelling particularly susceptible to counteracting effects, mean stratification and/or air-sea heat fluxes. The surface expression of the upwelling can also be delayed by the time it takes for the upwelling to draw deep waters to the surface. Furthermore, biannual baroclinic coastal trapped waves with amplitude $\sim 10-20 \mathrm{~m}$ modulate the upwelling seasonal cycle (Kounta et al. 2018) and may also complicate interactions between wind forcing and the SST response. Again, the MMM is significant at the $95 \%$ confidence level all year 
months and relatively close to the observations. Therefore, no systematic wind bias plagues the 358 climate simulations in the SMUS.

\section{2.b: Effect of the offshore Ekman Pumping}

The Ekman suction/pumping averaged along $16^{\circ} \mathrm{W}$ to $20^{\circ} \mathrm{W}$ is defined as:

$$
\left\langle U I_{\text {wind }}^{\text {suc }}\right\rangle=\left\langle\frac{1}{{ }_{w} f} \nabla \times\right\rangle_{\text {longitude }}
$$

where $\nabla \times$ is the curl of wind stress. This term is expressed in $m \cdot d a y^{-1}$. Given that the wind stress values that we use are located at the center of our working grid cells following several interpolations, it is not entirely clear whether the nearshore integration bound should be right at the coast or one grid cell away. We choose to include the grid cell closest to shore. Doing otherwise slightly changes our results quantitatively but does not affect our conclusions (not shown).

In Fig. 5 both observational dataset (first two columns of each panels) show that $\left\langle U I_{\text {wind }}^{\text {suc }}\right\rangle_{s}$ is maximum in winter (Fig.5.b) and $\left\langle U I_{\text {wind }}^{\text {suc }}\right\rangle_{n}$ in spring (Fig.5.a). This mainly follows the seasonality of the meridional wind stress intensity seen in Fig.4. Models generally yield stronger values than the observations. This tendency is particularly marked in the CCSM4, CESM1, GFDL, MIROC, and MRI groups. INM is the only simulation which exhibits negative (downwelling) values during spring in the nSMUS. As observed for Ekman transport, the MMM is close to the observations and significantly different from zero at the $95 \%$ level all year months.

\section{3: A counteracting effect: the onshore geostrophic flow}

As discussed by Marchesiello and Estrade (2010) and Ndoye et al. (2017) for example, the region of southern CUS region is characterized by a southward gradient of sea surface height which drives an onshore geostrophic flow. This flow can produce a convergence of water near the coast and therefore counteract the upwelling. Jacox et al. (2018) unambiguously demonstrate that upwelling indices accounting for this geostrophic contribution provide an improved characterization of the 
380 local vertical transport. In order to quantify this effect, we have examined the SSH climatology from the AVISO satellite data and the GODAS reanalysis, as well as in the climate models. The

SSH meridional gradient is computed as the difference between the SSH averaged over two regions bordering the SMUS region to the north and to the south (black boxes in Fig.1). In the validation data (Fig.6, first bars on the left), the SSH difference is indeed negative all year long, thus potentially inducing an onshore geostrophic flow. It undergoes semi-annual oscillations with maxima (resp. minima) in November -December and in June (resp. August-September and February to April). This effect thus seems to be maximum at the beginning and at the end of the upwelling season. It could explain the subtle time mismatch mentioned in section 3.2 between $\left\langle U I_{s s t}^{\text {cross }}\right\rangle$ and $\left\langle U I_{\text {wind }}^{d i v}\right\rangle$ with the geostrophic coastward flow preventing the SST cold anomalies to develop at the beginning and end of the upwelling season. In the climate models, the SSH difference is also always negative, but its seasonality differs strongly among models and hardly mimics the data. The SSH difference is strong all year long in many models (for example ACCESS1-0, ACCESS1-3, CESM1CAM5, CESM1-FASTCHEM, IPSL-CMA-LR, IPSL-CM5A-MR), which are in many cases those with low $\left\langle U I_{\text {sst }}^{\text {seas }}\right\rangle$ (Fig.2) and/or limited $\left\langle U I_{\text {sst }}^{\text {cross }}\right\rangle$ (Fig.3). This correspondence could confirm the counteracting effect of this geostrophic flow on the upwelling signature. In other models, the SSH difference is relatively weak (eg: CNRM, GFDL, LASG-IAP, LASG-CESS). Averaging over this diversity of model responses yields a weak seasonal cycle for the MMM but the timings for the two seasonal minima (only August-September) and maxima are correct. The MMM is not significantly different from zero.

Note that the choice of the offshore location where the cross-shore geostrophic transport should be computed is a source of difficulty. It may seem natural to compute it as close to the shore as possible (Jacox et al. 2018). In the models used here, doing so did not affect the results (not shown). 
On the other hand, it should be kept in mind that in reality and in finer resolution simulations, alongshore pressure gradients are significantly affected by the transition between the open/deep ocean and the continental shelf. Viscous effects may also become important nearshore. Therefore, we have used reference points situated slightly offshore as several studies have done (Colas et al. 2008; Marchesiello and Estrade, 2010;).

\section{4:Quantitative assessment of the upwelling rate}

We now propose to integrate the terms diagnosed above that contribute to the upwelling of subsurface water so as to provide a bulk assessment of the upwelling rate. This integration is performed over the entire upwelling area defined as $\left[12^{\circ} \mathrm{N}-20^{\circ} \mathrm{N}\right] /\left[16^{\circ} \mathrm{W}-20^{\circ} \mathrm{W}\right]$ and over the whole upwelling season running from November to May. Fig.7.a (green bars) shows the integrated effect of $U I_{\text {wind }}^{\text {div }}$. Here, we assume that all the water volume displaced zonally due to Ekman divergence along the coast is fed by upwelling, thereby neglecting any possible convergence/divergence of the alongshore flow (Yoon and Philander 1982). Under this simplifying assumption, the integrated $U I_{\text {wind }}^{d i v}$ terms leads to an upwelling of 1.2 to $1.4 S v$ in the observations and reanalysis, while the models range from $1 S v$ (CESM1-CAM5-1-FV2, CESM1-WACC, GISS family, HadCM3) to 2.25 $S v$ (HadGEM2-AO). The integral of the $U I_{\text {wind }}^{\text {suc }}$ term (yellow bars) computed from QuikSCAT and TropFlux both yield an upwelling of about $1.1 S v$ to $1.3 S v$. In both wind data sets, the effect of $U I_{\text {wind }}^{d i v}$ slightly dominates over $U I_{\text {wind }}^{\text {suc }}$ with a ratio between the two contributions of 1.6 (QuikSCAT) to 1.9 (TropFlux). The models tend to systematically overestimate $U I_{\text {wind }}^{d i v}$. The integrated value of the Ekman suction in the models ranges between 0.25-0.5 Sv (ACCESS1 and IPSL families) and about 2.75 Sv (HadGEM2-AO). The spread is larger for $U I_{w i n d}^{s u c}$, with some models overestimating the data and others underestimating them. $U I_{\text {wind }}^{d i v}$ dominates over $U I_{\text {wind }}^{\text {suc }}$ in 22 out of the 45 simulations for which the computation was possible (ACCESS, CSIRO-BOM, CNRM, CMCC, 
IPSL, MPI). Similar ratios as in the data are found in several individual models (BCC, EC-EARTH, CCSM4, CESM1). In the MMM, the contribution of $U I_{\text {wind }}^{d i v}$ is $1.62 S v+/-0.08$ while the $U I_{\text {wind }}^{s u c}$ induces $1.08 \mathrm{~Sv}+/-0.19$ of upwelling. Both components are $20-50 \%$ above observed values but their ratio corresponds quite well to what is found in the data (1.5). No significant difference in terms of the relative importance of the two Ekman processes was found when considering the southern and the northern sectors separately (not shown).

The physical and biogeochemical responses to coastal divergence and Ekman suction differ in important ways (Capet et al. 2004; Renault et al. 2016). As a first approach, the two may nonetheless be added up to provide an estimate of upwelling strength. Jacox et al. (2018) have recently suggested that the effect of Ekman processes should be estimated globally from the integration of Ekman transport along the boundaries (north, west, and south) of the region of interest. Comparison of this approach with the one proposed here has shown that both methodologies generally yield very similar results (not shown). In the validation data sets, the difference is less than 5\%, with the Jacox et al. (2018)'s approach leading to slightly stronger results, while the multimodel mean is weakened by approximately $10 \%$. A final refinement consists in accounting for the effect of the onshore geostrophic transport. The latter can be estimated as follows:

$$
T_{\text {geo }}=M L D \cdot \frac{g}{f}\left(S S H_{\text {north }} \quad S S H_{\text {south }}\right)
$$

where $T_{g e o}$ is the vertical transport (in $S v$ ) due to the zonal current generated from the meridional SSH gradient in the mean of Mixed Layer Depth (MLD, in meters) in the SMUS region, $g$ is the gravity coefficient ( $\left.g=9.81 \mathrm{~m}^{-2} \mathrm{~s}^{-2}\right), S S H_{n o r t h}-S S H_{\text {south }}$ is the meridional difference of sea surface height as computed in section 3.3. $T_{\text {geo }}$ is thus an estimate of the zonally averaged geostrophic transport in the SMUS region. The zonal averaging is such that the transport is centered at $18^{\circ} \mathrm{W}$ in 
water depths of $2000 \mathrm{~m}$ or more. As apparent in (5), we only account for the transport within the mixed layer (see Marchesiello and Estrade, 2010). $T_{g e o}$ is counted negative eastward following the sign convention used to quantify the upwelling. The result of this computation is shown in black in Fig.7.a. All models and validation datasets show a negative (counteracting) contribution of this term. Note though that, as for the Ekman divergence, a net geostrophic onshore flow at $18^{\circ} \mathrm{W}$ may in part be linked to an intensification of alongshore currents $\left(\frac{v_{g e o}}{y}>0\right)$, and not only counteracting the upwelling. The MRI model is probably a case where this effect plays an important role (if not the geostrophic onshore effect would produce an unrealistic downwelling transport of $6 S v$ ). In the other models, $T_{\text {geo }}$ ranges from $0.25 S v$ (ACESS-1-3) to $2 S v$ (CNRM family and CESM1-CAM5). The contribution of the geostrophic term is stronger in the MMM (1.59 Sv+/- 0.56, computed from only 22 simulations) than in the validation datasets ( $0.54 S v$ and $0.5 S v$ respectively). This 3 -fold bias indicates a possibly important model deficiency that would warrant further investigation.

As a first approximation of the upwelling intensity, we thus consider the integrated sum of the Ekman transport $\left(U I_{\text {wind }}^{\text {div }}\right)$, the Ekman suction $\left(U I_{\text {wind }}^{s u c}\right)$ and the geostrophic flow in the mixed layer $T_{g e o}$. We refer to this sum (Ekman processes and geostrophic flow) as the total upwelling index $\left(U I_{\text {total }}\right)$. This latter therm is $\sim 1.5 S v$ to $1.75 S v$ in the two data estimations respectively). Because of the very strong effect of the onshore geostrophic flow, $U I_{\text {total }}$ is negative in MRI, suggesting a downwelling. This result is inconsistent with the integrated vertical velocity over the region (grey bar) and with the SST-derived indices shown in Fig.2 and Fig.3. This being said, MRI is one of the models with weak upwelling signal in $\left\langle U I_{s s t}^{\text {seas }}\right\rangle$. The downwelling effect of SSH may thus indeed be relatively strong in this model but as indicated above, we suspect that the approximations underlying the construction of $U I_{\text {total }}$ are not fully valid in this model. In all the other models, $U I_{\text {total }}$ is positive and ranges between $0.25 S v$ and $\sim 2 S v$ (Fig.7.b) which is lower than or in 
the range of the estimates based on observations (1.5 Sv to $1.75 S v)$. The MMM value $(0.75 S v+/-$ $0.5)$ is more than $50 \%$ smaller.

$U I_{\text {total }}$ is approximatively equal to a direct estimation of the upwelling flux from vertical velocities diagnosed from the models ( $U_{w}$, Fig. $7 \mathrm{~b}$, see appendix B for details) for about one third of the models. For the CNRM-CM5 and CESM models, $U I_{\text {total }}$ is well above the effective model upwelling rate, suggesting again the role played by convergences of the meridional flow as a response to the Ekman divergence, and/or other neglected process. IPSL is the only family in which $U_{w}$ is much stronger than estimation of upwelling transport. The MMM is roughly $0.61 S v+/-0.2$ which a difference less than $14 \%$ of total estimation.

\section{Evolution of the senegalo-mauritanian upwelling as projected in global}

\section{warming scenarios.}

We now use the different indices introduced in section 3 to explore the evolution of the SMUS towards the end of the $21^{\text {st }}$ century in the RCP8.5 simulations. We consider the indices on average over the whole upwelling season, running from November to May. The MMM values correspond to the average of the changes of each individual simulations. As introduced in section 2, the significance of these changes is evaluated with a student test of the mean, considering that each simulation is independent. The subscript $s$ following the percentage of change in MMM marks the significance of changes at the $95 \%$ level. We also indicate the number of models that agree on the sign of a given projected change, as in Christensen et al. (2013) and Parvathi et al. (2017) for example.

Fig. 8 shows the projected change of the SST-based upwelling signatures averaged in the two SMUS subregions, expressed in percent of the historical value. Most simulations exhibit a

decrease of $\left\langle U I_{s s t}^{\text {seas }}\right\rangle_{n}$ (dark blue bars in Fig.8.a). The decrease lies between 5 and $15 \%$ of the 
historical value for most of the models. The MMM shows a decrease of $8+/-2 \%$ and $92.5 \%$ of the models agree on the sign of this change. Note that both the minimum and maximum climatological SST are expected to rise under the effect of global warming. A separate analysis has shown that, on average over the SMUS region, the sea surface temperature of the coldest climatological month increases more than the one of the warm season (not shown). This explains the reduction of the amplitude of the seasonal cycle and tends to suggest that it is indeed due to a reduction of the upwelling. Yet, this attribution is ambiguous because other processes such as air-sea heat fluxes and horizontal transports may be altered by climate change in a way that also impacts the SST seasonal cycle. Most models also exhibit a decreasing winter $\left\langle U I_{s s t}^{\text {cross }}\right\rangle_{n}$ in the future, with the MMM relative change being significantly negative. Because this index has very weak values in some historical simulations during the upwelling season, the percentage of change may be very large. Therefore, we show the percentage of change divided by 10 for clarity of the figure. The multi-model mean change of $\left\langle U I_{s s t}^{\text {cross }}\right\rangle_{n}$ is $65+/-23 \% \%^{s}$. Again, a majority of models $(90 \%)$ agree on the sign of this evolution. To conclude, in nSMUS, the SST upwelling signatures are well represented in the CMIP5 simulations (section 3.1), and their evolution into the end of the $21^{\text {st }}$ century provides some consistent signs of upwelling reduction.

In sSMUS (Fig.8.b), the decrease of $\left\langle U I_{\text {sst }}^{\text {seas }}\right\rangle_{s}$ reaches $10 \%$ to $15 \%$ in most of the models. A few of them show a strengthening of this index in the future (CSIRO-QCCCE, CMCC-CESM, EC-EARTH, GFDL-ESM2 and IPSL-CM5B-LR). Overall, the MMM projects a change of similar amplitude as in the north $(9+/-3 \%$ s $)$, with $87.5 \%$ of models agreeing on the sign of the change). In this region, the projected change of $\left\langle U I_{s s t}^{\text {cross }}\right\rangle_{s}$ is generally negative as well but weaker than in the north, and with less robustness (the index increases in 30\% of the models). The MMM decreases by $40+/-37 \%^{s}$. This strong relative change is a consequence of the small $\left\langle U I_{s s t}^{\text {cross }}\right\rangle_{s}$ value (close to zero) 
in the MMM for the present period (Fig.3.b). Further analysis has shown that the MMM change is insignificant during the beginning of the upwelling season (November and January) and only marginally significant during the core upwelling season (December and February to April, figure not shown). Overall in the sSMUS, both SST signatures suggest an upwelling reduction as in the north but these results need to be considered with caution as large biases were found in the representation of the upwelling SST signal over the historical period and the projected changes are less consistent than in the north.

Fig.9.a displays the responses of wind upwelling indices in the nSMUS. While the representation of $\left\langle U I_{\text {wind }}^{d i v}\right\rangle_{n}$ is very consistent among models over the historical period (Fig.4.b), the response of this index to climate change is approximately evenly split between increasing and decreasing signal for the future (green bars). Changes range from $-5 \%$ to $5 \%$ roughly. The MMM exhibits an insignificant reduction of $1.2+/-1.8 \%$. A closer check at the $\left\langle U I_{\text {wind }}^{d i v}\right\rangle_{n}$ projected changes for individual models and individual months reveals noisy patterns with many sign changes from one month to the next (not shown). This lack of consistency among the winter model responses over this region was also noted by Rykaczewski et al. (2015). On the other hand, $\left\langle U I_{\text {wind }}^{\text {div }}\right\rangle$ changes for summer indicate a more robust upwelling reduction consistent with the results of Wang et al. (2015) and Rykaczewski et al. (2015) (not shown). In this latitudinal band, the changes in Ekman suction are much more consistent: $89 \%$ of the models show a projected increase of $\left\langle U I_{\text {wind }}^{s u c}\right\rangle_{n}$ (yellow bars), favorable to an increase of the upwelling, in winter. The MMM intensification $\left(18+/-7 \%{ }^{s}\right)$ is not directly consistent with the SST-based results described above but Ekman pumping is known to exert limited second order effects on SST (Doi et al. 2009; Capet et al. 2004). A shift in the large scale atmospheric pressure system in the Atlantic (see Discussion below) is responsible for this situation where $\left\langle U I_{\text {wind }}^{\text {suc }}\right\rangle$ increases while $\left\langle U I_{\text {wind }}^{\text {div }}\right\rangle$ decreases. 
In the sSMUS (Fig.9.b), the climate models show a much more consistent response of 542 the Ekman divergence, with a general agreement on a reduction of the winter-time offshore Ekman transport in the future (CSIRO-QCCCE and MPI family excepted). The MMM indicates a

statistically significant reduction of $9+/-2 \%$ of $\left\langle U I_{\text {wind }}^{\text {div }}\right\rangle_{s}$, with $92 \%$ models agreeing on the sign of this change. The projected change of the $\left\langle U I_{\text {wind }}^{\text {suc }}\right\rangle_{s}$ is also more homogeneous. A large group of models indicate a reduction of $\sim 10 \%$. The reduction reaches $15 \%$ or more in many other (for example BCC, GFDL family and MIROC-ESM). Conversely, $\left\langle U I_{w i n d}^{s u c}\right\rangle_{s}$ increases moderately in INM (where we have found a negative historical $\left\langle U I_{\text {wind }}^{\text {suc }}\right\rangle_{n}$ in section 3.2.b) and MPI models. The MMM reduction amounts to $5+/-2 \%$. The $\left\langle U I_{\text {wind }}^{\text {suc }}\right\rangle$ and $\left\langle U I_{\text {wind }}^{\text {div }}\right\rangle$ changes are qualitatively consistent with the decrease of the SST-based indices seen in Fig. 8b.

As discussed above, the upwelling dynamics is a priori influenced by a combination of coastal divergence, Ekman pumping, and across-shore geostrophic transport. Because of a poor availability of MLD and SSH for future simulations, the evolution of geostrophic flow could only be estimated in 18 simulations (Fig.10) and results are inconclusive: the downwelling associated with this term increases in some simulations and decreases in others. The $T_{\text {geo }} \mathrm{MMM}$ change, which is downwelling-favorable, is consequently very weak and lacks statistical robustness. As for the net upwelling index $U I_{\text {total }}$, it exhibits a robust decrease of $8+/-7 \%^{s}$ this tendency is found in 14 simulations out of the 18 ones in which the diagnostic could be computed. We have tried to corroborate this result by examining the model vertical velocities. The projected changes for the MMM vertical transport in the SMUS exhibit a very weak decrease in the future but this reduction is not significant. More problematically, the differences between vertical transport and $U I_{\text {total }}$ varies widely from model to model for present-time conditions (Appendix B, Fig. 7b) and we are not able 
to explain such differences. The reader is referred to Oyarzún and Brierley (2018) for a comprehensive analysis of the vertical velocities in climate models.

\section{Discussion}

The effects of climate change on upwelling systems has been the subject of ample research in the last decade but the sector of the Canary system situated south of $\sim 20^{\circ} \mathrm{N}$, the SMUS, remains a blind spot in that respect. The focus of this work is the long-term winter/spring upwelling evolution of the SMUS. To this end, five upwelling indices based on sea surface temperature, surface wind stress and sea surface height have been defined, compared and combined. The two indices based on SST aim at describing the surface thermal signature of the SMUS upwelling, in space (inshore-offshore SST contrast) and time (seasonality of the upwelling). Although this is a restrictive view of the upwelling, these two indices have the advantage of being based on a well-observed variable so that they can be properly constrained by observations. The other three indices are based on the surface wind stress and meridional gradients of sea level. They aim at quantifying key mechanisms implicated in the generation of upwelling vertical velocities: coastal divergence of the Ekman transport, Ekman suction, and possible counteracting effects due to convergences of the geostrophic flow for the first four indices. Our work distinguishes two SMUS sectors, north and south of Cape Verde, located at $\sim 15^{\circ} \mathrm{N}$. We have compared the four indicators defined above. Unfortunately, pairwise inter-model correlations were found to be insignificant, both on the whole SMUS region and on the northern and southern ones separately (not shown).

In the south, all indices are consistent with an upwelling reduction toward the end of the $21^{\text {st }}$ century. This result is particularly robust as it can be found in the MMM as well as in a large fraction of individual CMIP5 models. Changes are most pronounced during the core of the upwelling period (February-April) but they are consistent over the entire period when upwelling winds are established (October-June). In the north, the evolution of the SST indices is also 
consistent with a tendency to upwelling reduction in winter and spring but the dynamical indices of upwelling intensity indicate otherwise: we found insignificant changes in coastal Ekman divergence and an increase of Ekman suction. Our attempt to provide more elaborate assessments of the upwelling rates have remained inconclusive, in part because many of the CMIP5 simulations do not offer the model fields necessary to evaluate the changes in mixed layer geostrophic circulation (needed to compute $U I_{\text {total }}$ ) or the true upwelling rates into the mixed layer (Appendix B). This is an important caveat given the magnitude of the upwelling compensation induced by geostrophic currents, which was confirmed by our analyses. Further progress will presumably require downscaling experiments as in Oerder et al. (2015).

In spite of their consistency, we regard the evolution of upwelling thermal signatures $U I_{s s t}^{\text {seas }}$ and $U I_{s s t}^{\text {cross }}$ with caution. Indeed SST and its long-term evolution under changing climate conditions are determined by complex interactions between processes of different nature involving a wide range of time scales and nonlinear feedbacks between them (Wahl et al. 2011; Jia and Wu 2013). Several additional processes, not investigated here, are also possibly implicated in the SST response to the surface wind in general and in the upwelling regions in particular. The mesoscale turbulence (Gruber et al. 2011) and the chlorophyll concentration (Hernandez et al. 2017) are examples of possible candidates. The subsurface stratification also certainly influences the SST response but its investigation has been left for a future study. The oceanic horizontal resolution (between $0.33^{\circ}$ and $3.7^{\circ}$ in the models used here) and vertical resolution also strongly limit the representation of the bathymetry and thus the representation of the oceanic signature of the upwelling in these models. Using these SST indicators in future studies should take all these limitations into account. An important premise of the present study has been that upwelling in the eastern tropical Atlantic is a key determinant of regional SST and remains so in the future. In such conditions, it was reasonable to expect that changes in the wind regime leading to modifications of 
the net volume of upwelled water would primarily control the SST evolution (colder resp. warmer when upwelling-favorable winds increase resp. decrease). In a system where SST spatial contrasts are so tightly controlled by the rate of wind-induced entrainment of subsurface water into the mixed layer, it indeed seems reasonable to assume that temporal SST evolution will mainly be determined by how this rate changes. This is actually observed on a broad range of scales, from synoptic (Ndoye et al. 2014), to inter annual (Roy 1989; Blanke et al. 2002), or even multi-decadal (Pardo et al. 2011; Seo et al. 2012). Nevertheless inter-model pairwise correlation of thermal and dynamical indices is in general not significant, primarily because of uncertainties in the SST-based indices.

On the other hand, climate models are imperfect representations of the real ocean. One important limitation is the representation of fine-scale processes such as coastal upwellings, whose typical across-shore scale $L$ and intensity $w$ are linked by the relation $U I_{\text {wind }}^{d i v} \sim L . . w$. Because of their coarse resolution, the physics of coastal upwelling cannot be properly resolved in climate models, so $L$ is determined by numerical considerations and we have $L \sim O(d x)$ being grossly overestimated. An important consequence is that $w$ is unrealistically small (e.g., see Capet et al. 2008). Overall, the influence of cold water entrainment into the mixed layer is spread spatially and locally greatly diminished, hence the possibility for other processes (changes in cloud cover, changes in relative humidity and evaporative heat flux (Hourdin et al. 2015), changes in lateral advection of heat by Sverdrup transport (Xu et al. 2014; Small et al. 2015) to compete with upwelling modifications and control trends in SST, and its spatio-temporal contrasts. The SMUS mixed layer heat balance is relatively subtle (Faye et al. 2015) and its evolution may involve more than just upwelling changes, especially in modeling systems where upwelling is weakened by numerical limitations. For example, an increase of the poleward Sverdrup transport due to changes in wind stress curl (Fig.9) could produce a moderate warming along the African coast and explain 
the tendency for SST based indices to decrease in CMIP models, despite the absence of significant changes in $\left\langle U I_{\text {wind }}^{d i v}\right\rangle_{n}$. Pending in-depth investigations of the present and future mixed layer heat budgets in CMIP runs (which would require model outputs rarely available from CMIP5 runs) we tend to place more confidence in the conclusions drawn from changes obtained for the dynamical indices $\left(U I_{\text {wind }}^{\text {div }}\right.$ and $\left.U I_{\text {wind }}^{\text {suc }}\right)$.

To test the physical soundness of the trends emerging from the dynamical indices ( $U I_{\text {wind }}^{\text {div }}$ and $U I_{\text {wind }}^{s u c}$ ) and try to explain the differences between northern and southern SMUS we propose additional analyses pertaining to the main atmospheric pressure centers and their possible spatial shift between present and future conditions. The Azores high, the Sahara-Sahelien heat low and the ITCZ are a priori the dominant centers of action in the region (Fig.11.a) whose long-term changes (e.g, displacements) can influence the SMUS wind regime. Fluctuations in the position of the Azores anticyclone (AA) have recently been implicated in the synoptic/intra-seasonal variability of upwelling winds offshore of Senegal (Kounta, pers com). Its influence on upwelling historical trends for the period 1981-2012 has also been previously noted by Cropper et al. (2014). As for the ITCZ, its meridional migration may play a key role in the seasonal interruption of upwelling winds over the southern SMUS. Indicators of the meridional position of the AA and ITCZ over the eastern Atlantic are computed for historical and future conditions (Fig.12). In general accordance with the recent findings of Byrne et al. (2018) on the change of the zonally averaged ITCZ location, no clear tendency is found for the position of the ITCZ in our sector of interest: the historical and future positions of the ITCZ are virtually identical for the MMM given the resolution of the common regular grid used the analysis. This figure also confirms the fact that the ITCZ, diagnosed from the maximum precipitation, is generally located further south than in the GPCP observations in the region between $15^{\circ} \mathrm{W}$ and $30^{\circ} \mathrm{W}$ limits (see Richter and Xie 2008) and also (Siongco et al. 2015). In contrast, results unambiguously point to a northward migration tendency for the AA. Differences 
between historical and future conditions are slightly above $1^{\circ}$ towards the north for the MMM, with $94.5 \%$ of the model agreeing on the migration direction. This result is consistent with those of Ma and Xie (2013), Sousa et al. (2017) and, more generally, with the projected expansion of the Hadley cell in a warming world (Lu et al. 2007).

A spatial view of these changes is given in Fig.11.b. The weak change of the ITCZ location in the eastern Atlantic is confirmed, although a northward shift is evident in the west, away from our region of interest. The northward shift of the AA manifests in the form of a positive SLP anomaly over the whole mid-latitudes and a negative anomaly further south. This latter anomaly is not purely zonal. It is more confined in the subtropical eastern Atlantic and appears as the oceanic prolongation of a clear cyclonic anomaly over land that is produced by anomalous warming. The presence of this anomalous heat low is one important aspect in the hypothesis of Bakun (1990) but its spatial structure is such that the upwelling wind response varies meridionnally depending on the sector: its quasi-circular shape with a center at $20^{\circ} \mathrm{N}$, i.e., the northern limit of the SMUS, implies very different wind anomalies north and south of this latitude. In the north, upwelling winds tend to intensify, as also found in Sousa et al. (2017). On the other hand, anomalous winds rotate to westerlies in the nSMUS and progressively to south-westerlies in the sSMUS at $10^{\circ} \mathrm{N}$. This spatial structure of the wind anomalies differs from the annual mean picture emerging from Servain et al. (2014) for the historical period possibly because changes in atmospheric state are season dependent and trends in winter-spring do not reflect those for the annual mean. The SLP change is, on the other hand, consistent with the trends presented above for $\left\langle U I_{\text {wind }}^{d i v}\right\rangle$ and their differences between the northern and southern SMUS. Considered over the entire Canary current system, the Bakun hypothesis does not appear to hold (as noted by Rykaczewski et al. 2015 for all four upwelling systems) because SLP modifications due to climate change are shaped in good part by the evolution 
of the Hadley cell (zonally symmetric expansion and poleward migration of its descending branch) and by an intriguing Sahara-Sahelian heat low expansion that protrudes onto the ocean.

The wind anomaly also exhibits a notable curl in the nSMUS in agreement with the $\left\langle U I_{\text {wind }}^{s u c}\right\rangle_{n}$ changes (Fig.9.a). The sSMUS evolution is in fine more influenced by regional subtleties of the SLP changes (the zonal and meridional structure of the anomalous low) than by the larger scale northward shift of the AA. Processes at even finer scale unresolved in the CMIP5 simulations may further modulate the evolution of the SMUS wind regime (Boé et al. 2011).

\section{Conclusion}

The focus of this work was the long-term upwelling evolution in the SMUS region. To this end, five upwelling indices based on sea surface temperature, surface wind stress and sea surface height have been defined, compared and combined. The two indices based on SST aimed at describing the surface thermal signature of the upwelling, in space (inshore-offshore SST contrast) and time (seasonality of the upwelling). The other three indices were based on the surface wind stress and anomalous SSH and aimed at quantifying key mechanisms for the upwelling.

Amplitude of the SST seasonal cycle in the upwelling region is generally well represented in the climate models. In 34 simulations out of 47 , however, the index is underestimated in the southern part of the upwelling and the maximum is found north of $15^{\circ} \mathrm{N}$. This bias is suggestive of difficulties to reproduce the tropical Atlantic climate in the models. The SST contrast between the open ocean and the coast shows a clear seasonal cycle and it even changes sign in summer. Again, models usually have largest biases in the southern part of the senegalo-mauritanian upwelling, where this seasonality is not as clearly defined as in the observations. Interestingly, despite biases in terms of intensity, the seasonality of the Ekman drift, diagnosed from the surface wind stress, is on 
the contrary relatively well reproduced in the models, with a multi model mean very similar to the validation datasets in both SMUS subdomains.

We have also attempted to quantify the total volume of upwelled water. Our approach was based on the cumulative effect of two driving terms (Ekman drift and Ekman suction) and one damping term (geostrophic onshore flow). One strong limitation of this approach is the neglect of possible meridional/alongshore flow convergence. Specifically, a recent study has highlighted the seasonality of the slope current along West Africa (Kounta et al. 2018). This indirect estimation could also slightly overestimate the real upwelling volume by not distinguishing water upwelled through suction and divergence processes at the coast. Finally, the estimation of the geostrophic onshore flow was found to be inconsistent across models. Still, this estimation yields an upwelling ranging between $\sim 1.5 S v$ to $1.75 S v$ in the validation data. This amount tends to be underestimated in the MMM, where the volume of upwelled water is estimated to be $0.75 S v+/-0.5$. The volume of upwelled water due to the diagnostic vertical velocity of the models yields an even weaker estimation: $0.61 S v+/-0.2$, consistently with the approximations discussed above. Furthermore, note that these different averages are not performed over the exact same multi model ensemble due to restrictions data availability.

The response of the individual models to the RCP8.5 scenario is diverse in terms of amplitude but the general picture is a reduction of the upwelling toward the end of the $21^{\text {st }}$ century. The response of the thermal indices is in general more consistent among models and it is only partly consistent with the response of the dynamical indices. $\left\langle U I_{s s t}^{\text {seas }}\right\rangle$ is clearly reduced in the future, because the warming trends is accentuated in winter (upwelling-season) when SST is coldest. Consistently with this picture of a reduced upwelling effect on the SST, the offshore-coastal SST contrast decreases in most models in both the northern and southern SMUS region. The meridional wind stress is also projected to decrease during the $21^{\text {st }}$ century when averaged over the whole 
southern SMUS $\left(12^{\circ} \mathrm{N}-20^{\circ} \mathrm{N}\right)$. This projection of Ekman divergence is much more robust across models in the southern region, consistently with the large-scale anomalous SLP structure characterized by an anomalous heat low around $20^{\circ} \mathrm{N}$ (whose imprint extends over the ocean) and a northward shift of AA. A recent study in the Humboldt upwelling system in a subset of the CMIP5 models database has suggested an increasing wind stress projected in the poleward upwelling part in winter (Oyarzún and Brierley 2018). However, the authors shows that an increasing stratification will in parallel limit the effect of the wind below the surface. Such effect has not been investigated here.

In the northern part of SMUS, models split roughly equally into those suggesting an increase and a decrease of the wind divergence. The large scale circulation indeed shows that the anomalous wind circulation is primarily westward. Consistently with these large scale circulation changes, Ekman suction increases in nSMUS and decreases in sSMUS. In nSMUS, this is not directly consistent with the thermal indices. Over the whole southern SMUS region $\left(12^{\circ} \mathrm{N}-20^{\circ} \mathrm{N}\right)$, we found no significant change of the wind stress curl. Finally, the simple dynamical budget of the upwelling that we have proposed generally yields a weakening of the upwelling. The evolution of the vertical transport diagnosed from the vertical velocities computed online is inconclusive.

Our results generally show that the thermal indices are more sensitive to models deficiencies than the dynamical ones, which rely more on the large scale atmospheric circulation. Major efforts have recently been put on the reduction of tropical Atlantic biases (Richter 2015). Upcoming CMIP6 simulations are expected to benefit from them. While we have carried out a first exploration of the future of the SMUS upwelling with the CMIP5 models, we hope that the present study could be used as a benchmark framework to investigate the future of the coastal upwellings in the CMIP6 simulations. Consequences of the present study and of the projected future of the upwelling for fishery activities in Senegal also still deserves extensive attention. Renault et al. (2016) have shown 
that upwelling indices are not enough to evaluate primary production and fish stocks. Chavez and 753 Messié (2009) have even illustrated for example that Peru fish catch exceeds that from the other

$$
\begin{array}{ll}
10^{3} C_{d}=0.49+0.065 \mathrm{~V} & \text { for } 10 \quad V<25 \mathrm{m.s}{ }^{1} \\
10^{3} C_{d}=1.14 & \text { for } 3 \quad V<10 \mathrm{~m} . \mathrm{s}^{1} \\
10^{3} C_{d}=0.62+1.56 \mathrm{~V}^{-1} & \text { for } V<3 m . \mathrm{s}^{-1}
\end{array}
$$

Gill (1982), (pp 29) proposed another scaling, based on results of Smith (1980) for large wind speeds:

$$
\begin{array}{ll}
C_{d}=0.0011 & \text { for } V>3 m \cdot s^{-1} \\
10^{3} C_{d}=0.061+0.063 \mathrm{~V} & \text { for } 6<V<22 m \cdot s^{-1}
\end{array}
$$

The NOAA-TM-NMF S-SWFSC-231 rapport (1996) suggests to use the value of $C_{d}=0.0026$ with monthly mean data while Santos et al. (2012) used $C_{d}=0.0014$ for their study of the Moroccan upwelling zone $\left(22^{\circ} \mathrm{N}-33^{\circ} \mathrm{N}\right)$.

Over the SMUS region, the maximum wind speed is around $7 m \cdot s^{-1}$. We compared the meridional component of the wind stress computed online in the IPSL-CM5A-LR climate model to the wind 
stress computed offline using the meridional wind speed component from the same simulations with the drag coefficient values from Santos et al. (2012) and the two methods (equation (9), (10)) drag coefficient listed above (figure not shown). We have chosen to test only the meridional wind component because it is the strongest one in the SMUS region and most directly associated to the upwelling intensity. We found that the scaling proposed in Gill (1982) underestimate the meridional wind stress amplitude north of roughly $15^{\circ} \mathrm{N}$, in particular in summer north of $20^{\circ} \mathrm{N}$, as well as in winter between $12^{\circ} \mathrm{N}$ and $20^{\circ} \mathrm{N}$ which the season and the latitude band of the SMUS. The $C_{d}=$ 0.0014 scaling as used by Santos et al. (2012) yields the closest values to the observations. In all simulations where only the wind speed components are provided, the wind stress was thus computed using this latter scaling.

Appendix B: model upwelling from vertical velocities.

The net estimation of upwelling must in principle be consistent with the upward ocean mass transport diagnosed in the models (whenever available). However, this latter field is noisy (as recently emphasized by Oyarzún and Brierley 2018) and the depth at which the typical upwelling vertical velocity should be considered for comparison with upwelling indices is a difficult parameter to choose. Here, this depth has been chosen equal to the mixed layer depth averaged over the upwelling season (November to May) and over the SMUS region. In the models for which $U_{\text {total }}$ could not be computed (see last column in Table 1) we choose the depth where $U_{w}$ is maximum.

\section{Acknowledgements}

A. Sylla was supported for this study by a scholarship from IRD (Institut de Recherche pour le Développement), from the French Embassy in Senegal and from AMMA 2050 innovative fund (SCUS-2050 project grant number M0220428/1). The authors also acknowledge support from the Laboratoire Mixte International ECLAIRS2. This study benefited from the ESPRI computing and data center (https://mesocentre.ipsl.fr) which is supported by CNRS, Sorbonne Université, Ecole 
798 Polytechnique and CNES and through the ANR (Grant \#ANR-10-LABX-0018) and the European 799 FP7 IS-ENES2 project (Grant \#312979). 


\section{References}

Alpers, W., Brandt, P., Lazar, A., Dagorne, D., Sow, B., Faye, S., Hansen, M. W., Rubino, A., Poulain, P. M. and Brehmer, P. (2013) 'A small-scale oceanic eddy off the coast of West Africa studied by multi-sensor satellite and surface drifter data', Remote Sensing of Environment. Elsevier Inc., 129, pp. 132-143. doi: 10.1016/j.rse.2012.10.032.

Aristegui, J., Alvarez-Salgado, X. A., Barton, E. D., Figueiras, F. G. and Hernández-León, S. (2005) 'Oceanogrphy and fisheries of the Canary Current/Iberian region of the eastern north atlantic (18a, E)', The Sea, 14, pp. 877-932.

Arístegui, J., Barton, E. D., Álvarez-Salgado, X. A., Santos, A. M. P., Figueiras, F. G., Kifani, S., Hernández-León, S., Mason, E., Machú, E. and Demarcq, H. (2009) 'Sub-regional ecosystem variability in the Canary Current upwelling', Progress in Oceanography. Elsevier Ltd, 83(1-4), pp. 33-48. doi: 10.1016/j.pocean.2009.07.031.

Bakun, A. (1990) 'Coastal Ocean Upwelling', Science, 247(4939), pp. 198-201. doi: 10.1126/science.247.4939.198.

Bakun, A. and Nelson, C. S. (1991) 'The Seasonal Cycle of Wind-Stress Curl in Subtropical Eastern Boundary Current Regions', Journal of Physical Oceanography, 21(12), pp. 1815-1834. doi: 10.1175/15200485(1991)021<1815:TSCOWS>2.0.CO;2.

Barton, E. D., Field, D. B. and Roy, C. (2013) 'Canary current upwelling: More or less?', Progress in Oceanography. Elsevier Ltd, 116, pp. 167-178. doi: 10.1016/j.pocean.2013.07.007.

Bellenger, H., Guilyardi, E., Leloup, J., Lengaigne, M. and Vialard, J. (2014) 'ENSO representation in climate models: From CMIP3 to CMIP5', Climate Dynamics, 42(7-8), pp. 1999-2018. doi: 10.1007/s00382013-1783-z.

Benazzouz, A., Mordane, S., Orbi, A., Chagdali, M., Hilmi, K., Atillah, A., Lluís Pelegrí, J. and Hervé, D. (2014) 'An improved coastal upwelling index from sea surface temperature using satellite-based approach - 
The case of the Canary Current upwelling system', Continental Shelf Research, 81, pp. 38-54. doi: 10.1016/j.csr.2014.03.012.

Blanchette, C. A., Melissa Miner, C., Raimondi, P. T., Lohse, D., Heady, K. E. K. and Broitman, B. R. (2008) 'Biogeographical patterns of rocky intertidal communities along the Pacific coast of North America', Journal of Biogeography. John Wiley \& Sons, Ltd (10.1111), 35(9), pp. 1593-1607. doi: 10.1111/j.13652699.2008.01913.x.

Blanke, B., Roy, C., Penven, P., Speich, S., McWilliams, J. and Nelson, G. (2002) 'Linking wind and interannual upwelling variability in a regional model of the southern Benguela', Geophysical Research Letters, 29(24), pp. 41-1-41-4. doi: 10.1029/2002GL015718.

Boé, J., Hall, A., Colas, F., McWilliams, J. C., Qu, X., Kurian, J. and Kapnick, S. B. (2011) 'What shapes mesoscale wind anomalies in coastal upwelling zones?', Climate Dynamics, 36(11-12), pp. 2037-2049. doi: $10.1007 / \mathrm{s} 00382-011-1058-5$.

Boville, B. A. and Gent, P. R. (1998) 'The NCAR Climate System Model, Version One', Journal of Climate, 11, pp. 1115-1130. doi: 10.1175/1520-0442(1998)011<1115:tncsmv>2.0.co;2.

de Boyer Montégut, C., Madec, G., Fischer, A. S., Lazar, A. and Iudicone, D. (2004) 'Mixed layer depth over the global ocean: An examination of profile data and a profile-based climatology', Journal of Geophysical Research C: Oceans, 109(12), pp. 1-20. doi: 10.1029/2004JC002378.

Bravo, L., Ramos, M., Astudillo, O., Dewitte, B. and Goubanova, K. (2016) 'Seasonal variability of the Ekman transport and pumping in the upwelling system off central-northern Chile $\left(\sim 30^{\circ} \mathrm{S}\right)$ based on a highresolution atmospheric regional model (WRF)', Ocean Science, 12(5), pp. 1049-1065. doi: 10.5194/os-121049-2016.

Breugem, W. P., Chang, P., Jang, C. J., Mignot, J. and Hazeleger, W. (2008) 'Barrier layers and tropical Atlantic SST biases in coupled GCMs', Tellus, Series A: Dynamic Meteorology and Oceanography, 60(5), pp. 885-897. doi: 10.1111/j.1600-0870.2008.00343.x. 
Byrne, M. P., Pendergrass, A. G., Rapp, A. D. and Wodzicki, K. R. (2018) 'Response of the Intertropical Convergence Zone to Climate Change: Location, Width, and Strength', Current Climate Change Reports. Springer International Publishing, pp. 355-370. doi: 10.1007/s40641-018-0110-5.

Capet, X. J., Marchesiello, P. and McWilliams, J. C. (2004) 'Upwelling response to coastal wind profiles', Geophysical Research Letters, 31(13), pp. 1-4. doi: 10.1029/2004GL020123.

Capet, X., McWilliams, J. C., Molemaker, M. J. and Shchepetkin, A. F. (2008) 'Mesoscale to Submesoscale Transition in the California Current System. Part I: Flow Structure, Eddy Flux, and Observational Tests', Journal of Physical Oceanography, 38(1), pp. 29-43. doi: 10.1175/2007JPO3671.1.

Carr, M. E. and Kearns, E. J. (2003) 'Production regimes in four Eastern Boundary Current systems', DeepSea Research Part II: Topical Studies in Oceanography, 50(22-26), pp. 3199-3221. doi: 10.1016/j.dsr2.2003.07.015

Carton, J. A. and Giese, B. S. (2008) 'A Reanalysis of Ocean Climate Using Simple Ocean Data Assimilation (SODA)', Monthly Weather Review, 136(8), pp. 2999-3017. doi: 10.1175/2007MWR1978.1.

Chang, C. Y., Carton, J. A., Grodsky, S. A. and Nigam, S. (2007) 'Seasonal climate of the tropical Atlantic sector in the NCAR community climate system model 3: Error structure and probable causes of errors', Journal of Climate, 20(6), pp. 1053-1070. doi: 10.1175/JCLI4047.1.

Chavez, F. P. and Messié, M. (2009) ‘A comparison of Eastern Boundary Upwelling Ecosystems', Progress in Oceanography. Elsevier Ltd, 83(1-4), pp. 80-96. doi: 10.1016/j.pocean.2009.07.032.

Christensen, J. H., Krishna Kumar, K., Aldrian, E., An, S.-I., Cavalcanti, I. F. A., de Castro, M., Zhou, T. (2013). Climate phenomena and their relevance for future regional climate change. In T. F. Stocker, et al. (Eds.), Climate Change 2013: The Physical Science Basis. Contribution of Working Group I to the Fifth Assessment Report Intergovernmental Panel on Climate Change (pp. 1217-1308). Cambridge, UK, and New York: Cambridge University Press.

405 
Colas, F., Capet, X., McWilliams, J. C. and Shchepetkin, A. (2008) '1997-1998 El Niño off Peru: A numerical study', Progress in Oceanography. Pergamon, 79(2-4), pp. 138-155. doi: 10.1016/J.POCEAN.2008.10.015

Cropper, T. E., Hanna, E. and Bigg, G. R. (2014) 'Spatial and temporal seasonal trends in coastal upwelling off Northwest Africa, 1981-2012', Deep-Sea Research Part I: Oceanographic Research Papers. Elsevier, 86, pp. 94-111. doi: 10.1016/j.dsr.2014.01.007.

Dee, D. P., Uppala, S. M., Simmons, A. J., Berrisford, P., Poli, P., Kobayashi, S., Andrae, U., Balmaseda, M. A., Balsamo, G., Bauer, P., Bechtold, P., Beljaars, A. C. M., van de Berg, L., Bidlot, J., Bormann, N., Delsol, C., Dragani, R., Fuentes, M., Geer, A. J., Haimberger, L., Healy, S. B., Hersbach, H., Holm, E. V., Isaksen, L., Kallberg, P., Koehler, M., Matricardi, M., Mcnally, A. P., Monge-Sanz, B. M., Morcrette, J. J., Park, B. K., Peubey, C., de Rosnay, P., Tavolato, C., Thepaut, J. N. and Vitart, F. (2011) 'The ERA-Interim reanalysis: Configuration and performance of the data assimilation system', Quarterly Journal of the Royal Meteorological Society, 137(656), pp. 553-597. doi: 10.1002/qj.828.

DeWitt, D. G. (2005) 'Diagnosis of the tropical Atlantic near-equatorial SST bias in a directly coupled atmosphere-ocean general circulation model', Geophysical Research Letters. John Wiley \& Sons, Ltd, 32(1), pp. 1-4. doi: 10.1029/2004GL021707

Doi, T., Tozuka, T. and Yamagata, T. (2009) 'Interannual variability of the Guinea Dome and its possible link with the Atlantic Meridional Mode', Climate Dynamics, 33(7-8), pp. 985-998. doi: 10.1007/s00382009-0574-z.

Ducet, N., Le Traon, P. Y. and Reverdin, G. (2000) 'Global high-resolution mapping of ocean circulation from TOPEX/Poseidon and ERS-1 and -2', Journal of Geophysical Research: Oceans, 105(C8), pp. 1947719498. doi: 10.1029/2000JC900063.

Faye, S., Lazar, A., Sow, B. A. and Gaye, A. T. (2015) 'A model study of the seasonality of sea surface temperature and circulation in the Atlantic North-eastern Tropical Upwelling System', Frontiers in Physics, 3(September), pp. 1-20. doi: 10.3389/fphy.2015.00076. 
Fenberg, P. B., Menge, B. A., Raimondi, P. T. and Rivadeneira, M. M. (2015) 'Biogeographic structure of the northeastern Pacific rocky intertidal: The role of upwelling and dispersal to drive patterns', Ecography. John Wiley \& Sons, Ltd (10.1111), 38(1), pp. 83-95. doi: 10.1111/ecog.00880.

Gill, A. E. (1982) 'Atmosphere-Ocean Dynamics, Academic Press, San Diego’.

Gómez-Gesteira, M., De Castro, M., Álvarez, I., Lorenzo, M. N., Gesteira, J. L. G. and Crespo, A. J. C. (2008) 'Spatio-temporal upwelling trends along the Canary upwelling system (1967-2006)', in Annals of the New York Academy of Sciences, pp. 320-337. doi: 10.1196/annals.1446.004.

Gordon, C., Cooper, C., Senior, C. A., Banks, H., Gregory, J. M., Johns, T. C., Mitchell, J. F. B. and Wood, R. A. (2000) 'The simulation of SST, sea ice extents and ocean heat transports in a version of the Hadley Centre coupled model without flux adjustments', Climate Dynamics, 16(2-3), pp. 147-168. doi: $10.1007 / \mathrm{s} 003820050010$.

Grodsky, S. A., Carton, J. A., Nigam, S. and Okumura, Y. M. (2012) 'Tropical Atlantic Biases in CCSM4', Journal of Climate, 25(11), pp. 3684-3701. doi: 10.1175/JCLI-D-11-00315.1.

Gruber, N., Lachkar, Z., Frenzel, H., Marchesiello, P., Münnich, M., McWilliams, J. C., Nagai, T. and Plattner, G. K. (2011) 'Eddy-induced reduction of biological production in eastern boundary upwelling systems', Nature Geoscience. Nature Publishing Group, 4(11), pp. 787-792. doi: 10.1038/ngeo1273.

Halpern, D. (2002) 'Offshore Ekman transport and Ekman pumping off Peru during the 1997-1998 El Niño', Geophysical Research Letters, 29(5), pp. 19-1-19-4. doi: 10.1029/2001GL014097.

Hernandez, O., Jouanno, J., Echevin, V. and Aumont, O. (2017) 'Modification of sea surface temperature by chlorophyll concentration in the Atlantic upwelling systems', pp. 5367-5389. doi: 10.1002/2016JC012222.Received.

Huang, B., Hu, Z. Z. and Jha, B. (2007) 'Evolution of model systematic errors in the tropical atlantic basin from coupled climate hindcasts', Climate Dynamics. Springer-Verlag, 28(7-8), pp. 661-682. doi: $10.1007 / \mathrm{s} 00382-006-0223-8$. 
Hourdin, F., Gainusa-Bogdan, A., Braconnot, P., Dufresne, J. L., Traore, A. K. and Rio, C. (2015) 'Air moisture control on ocean surface temperature, hidden key to the warm bias enigma', Geophysical Research Letters, 42(24), pp. 10885-10893. doi: 10.1002/2015GL066764.

Jacox, M. G., Edwards, C. A., Hazen, E. L. and Bograd, S. J. (2018) 'Coastal Upwelling Revisited: Ekman, Bakun, and Improved Upwelling Indices for the U.S. West Coast', Journal of Geophysical Research: Oceans, pp. 1-19. doi: 10.1029/2018JC014187.

Jia, F. and Wu, L. (2013) 'A Study of Response of the Equatorial Pacific SST to Doubled-CO 2 Forcing in the Coupled CAM-1.5-Layer Reduced-Gravity Ocean Model', Journal of Physical Oceanography, 43(7), pp. 1288-1300. doi: 10.1175/JPO-D-12-0144.1.Kounta, L. X. Capet, J. Jouanno, N. Kolodziejczyk, B. Sow and A. T. Gaye, 2018: A model perspective on the dynamics of the shadow zone of the eastern tropical North Atlantic. Part 1: the poleward slope currents along West Africa, Ocean Science, Katlenburg-Lindau Vo.l 13,N5, 971. DOI:10.5194/os-14-971-2018

Large et Pond, 1982 (1982) 'Sensible and Latent heat Flux Measurements over Ocean', Journal of Physical Oceanography, 12 .

Lathuilière, C., Echevin, V. and Lévy, M. (2008) 'Seasonal and intraseasonal surface chlorophyll-a variability along the northwest African coast', Journal of Geophysical Research: Oceans, 113(5), pp. 20002004. doi: 10.1029/2007JC004433.

Lu, J., Vecchi, G. A. and Reichler, T. (2007) 'Expansion of the Headley cell under global warming', Geophysical Research Letters, 34(6), p. L06805. doi: 10.1029/2006GL028443.

Ma, J. and Xie, S. P. (2013) 'Regional Patterns of Sea Surface Temperature Change: A Source of Uncertainty in Future Projections of Precipitation and Atmospheric Circulation', Journal of Climate, 26(8), pp. 2482-2501. doi: 10.1175/JCLI-D-12-00283.1.

Marcello, J., Hernández-Guerra, A., Eugenio, F. and Fonte, A. (2011) 'Seasonal and temporal study of the northwest African upwelling system', International Journal of Remote Sensing, 32(7), pp. 1843-1859. doi: $10.1080 / 01431161003631576$ 
Marchesiello, P. and Estrade, P. (2010) 'Upwelling limitation by onshore geostrophic flow', Journal of Marine Research, 68(1), pp. 37-62. doi: 10.1357/002224010793079004.

Mason, E., Colas, F., Molemaker, J., Shchepetkin, A. F., Troupin, C., McWilliams, J. C. and Sangrà, P. (2011) 'Seasonal variability of the Canary Current: A numerical study', Journal of Geophysical Research: Oceans, 116(6), pp. 1-20. doi: 10.1029/2010JC006665.

McGregor, H. V, Dima, M., Fischer, H. W. and Mulitza, S. (2007) 'Rapid 20th-century increase in coastal upwelling off northwest Africa', Science, 315(5812), pp. 637-639. doi: 10.1126/science.1134839.

Mittelstaedt, E. (1991) 'The ocean boundary along the northwest African coast: Circulation and oceanographic properties at the sea surface', Progress in Oceanography, pp. 307-355. doi: 10.1016/0079$6611(91) 90011-\mathrm{A}$

Mote, P. W. and Mantua, N. J. (2002) 'Coastal upwelling in a warmer future', Geophysical Research Letters, 29(23), pp. 53-1-53-4. doi: 10.1029/2002GL016086.

Narayan, N., Paul, A., Mulitza, S. and Schulz, M. (2010) 'Trends in coastal upwelling intensity during the late 20th century', Ocean Science, 6(3), pp. 815-823. doi: 10.5194/os-6-815-2010.

Ndoye, S., Capet, X., Estrade, P., Sow, B., Dagorne, D., Lazar, A., Gaye, A. and Brehmer, P. (2014) 'SST patterns and dynamics of the southern Senegal-Gambia upwelling center', Journal of Geophysical Research: Oceans, 119(12), pp. 8315-8335. doi: 10.1002/2014JC010242.

Ndoye, S., Capet, X., Estrade, P., Sow, B., Machu, E., Brochier, T., Döring, J. and Brehmer, P. (2017) 'Dynamics of a "low-enrichment high-retention" upwelling center over the southern Senegal shelf', Geophysical Research Letters, 44(10), pp. 5034-5043. doi: 10.1002/2017GL072789.

Nelson, C. (1976) 'Wind stress and wind stress curl over the California Current', Pacific Environmental Group, National Fisheries Service, National Oceanic and Atmospheric Administration, Technical Report, 714(1963), p. 89 
Nykjær, L. and Van Camp, L. (1994) 'Seasonal and interannual variability of coastal upwelling along northwest Africa and Portugal from 1981 to 1991', Journal of Geophysical Research, 99(C7), p. 14197. doi: 10.1029/94JC00814.

Oerder, V., Colas, F., Echevin, V., Codron, F., Tam, J. and Belmadani, A. (2015) 'Peru-Chile upwelling dynamics under climate change', Journal of Geophysical Research: Oceans. Wiley-Blackwell, 120(2), pp. 1152-1172. doi: 10.1002/2014JC010299.

Oyarzún, D. and Brierley, C. M. (2018) 'The future of coastal upwelling in the Humboldt current from model projections', Climate Dynamics. Springer Berlin Heidelberg, 0(0), pp. 1-17. doi: 10.1007/s00382018-4158-7.

Pardo, P. C., Padín, X. A., Gilcoto, M., Farina-Busto, L. and Pérez, F. F. (2011) 'Evolution of upwelling systems coupled to the long-term variability in sea surface temperature and Ekman transport', Climate Research, 48(2-3), pp. 231-246. doi: 10.3354/cr00989.

Pauly, D. and Christensen, V. (1995) 'Primary production required to sustain global fisheries (vol 374, pg 255, 1995)', Nature, 376(6537), p. 279.

Parvathi, V., Suresh, I., Lengaigne, M., Izumo, T. and Vialard, J. (2017) 'Robust Projected Weakening of Winter Monsoon Winds Over the Arabian Sea Under Climate Change', Geophysical Research Letters, 44(19), pp. 9833-9843. doi: 10.1002/2017GL075098.

Pickett, M. H. (2003) 'Ekman transport and pumping in the California Current based on the U.S. Navy's high-resolution atmospheric model (COAMPS)', Journal of Geophysical Research, 108(C10), pp. 1-10. doi: 10.1029/2003JC001902.

Praveen Kumar, B., Vialard, J., Lengaigne, M., Murty, V. S. N., McPhaden, M. J., Cronin, M. F., Pinsard, F. and Gopala Reddy, K. (2013) 'TropFlux wind stresses over the tropical oceans: Evaluation and comparison with other products', Climate Dynamics, 40(7-8), pp. 2049-2071. doi: 10.1007/s00382-012-1455-4. 
Rayner, N., Parker, D., Horton, E., Folland, C., Alexander, L., Rowell, D., Kent, E., Kaplan, A., (2003). 'Global analyses of sea surface temperature, sea ice, and night marine air temperature since the late nineteenth century.' J. Geophys. Res. 108(D14), 4407, doi:10.1029/2002JD002670.

Renault, L., Deutsch, C., McWilliams, J. C., Frenzel, H., Liang, J. H. and Colas, F. (2016) 'Partial decoupling of primary productivity from upwelling in the California Current system', Nature Geoscience, 9(7), pp. 505-508. doi: 10.1038/ngeo2722.

Riahi, K., Rao, S., Krey, V., Cho, C., Chirkov, V., Fischer, G., Kindermann, G., Nakicenovic, N. and Rafaj, P. (2011) 'RCP 8.5-A scenario of comparatively high greenhouse gas emissions', Climatic Change, 109(1), pp. 33-57. doi: 10.1007/s10584-011-0149-y.

Richter, I. and Xie, S. P. (2008) 'On the origin of equatorial Atlantic biases in coupled general circulation models', Climate Dynamics, 31(5), pp. 587-598. doi: 10.1007/s00382-008-0364-z.

Richter I, Xie S-P, Wittenberg AT, Masumoto Y (2012) Tropical Atlantic biases and their relation to surface wind stress and terrestrial precipitation. Clim Dyn 38:985-1001. doi:10.1007/ s00382-011-1038-9

Richter, I., Xie, S. P., Behera, S. K., Doi, T. and Masumoto, Y. (2014) 'Equatorial Atlantic variability and its relation to mean state biases in CMIP5', Climate Dynamics, 42(1-2), pp. 171-188. doi: 10.1007/s00382012-1624-5.

Richter, I. (2015) 'Climate model biases in the eastern tropical oceans: Causes, impacts and ways forward', Wiley Interdisciplinary Reviews: Climate Change, 6(3), pp. 345-358. doi: 10.1002/wcc.338.

Roy, C. (1989) 'Fluctuation des vents et variabilité de l'upwelling devant les côtes du Sénégal.', Oceano. Acta., 12(4), pp. 361-369.

Roy, C. (1998) 'An upwelling-induced retention area off Senegal: a mechanism to link upwelling and retention processes', South African Journal of Marine Science, 19(1), pp. 89-98. doi: $10.2989 / 025776198784126881$. 
1016 Rykaczewski, R. R., Dunne, J. P., Sydeman, W. J., García-Reyes, M., Black, B. A. and Bograd, S. J. (2015)

1017 'Poleward displacement of coastal upwelling-favorable winds in the ocean's eastern boundary currents 1018 through the 21st century', Geophysical Research Letters, 42(15), pp. 6424-6431. doi: $1019 \quad 10.1002 / 2015 G L 064694$.

1020 Santos, a. M. P., Kazmin, A. S. and Peliz, Á. (2005) 'Decadal changes in the Canary upwelling system as 1021 revealed by satellite observations: Their impact on productivity', Journal of Marine Research, 63(2), pp. 359-379. doi: 10.1357/0022240053693671.

1023 Santos, F., DeCastro, M., Gómez-Gesteira, M. and Álvarez, I. (2012) 'Differences in coastal and oceanic 1024 SST warming rates along the Canary upwelling ecosystem from 1982 to 2010', Continental Shelf Research, 1025 47, pp. 1-6. doi: 10.1016/j.csr.2012.07.023.

1026 Seo, H., Brink, K. H., Dorman, C. E., Koracin, D. and Edwards, C. A. (2012) 'What determines the spatial 1027 pattern in summer upwelling trends on the U.S. West Coast?', Journal of Geophysical Research: Oceans, 1028 117(8), pp. 1-11. doi: 10.1029/2012JC008016.

1029 Servain, J., Caniaux, G., Kouadio, Y. K., McPhaden, M. J. and Araujo, M. (2014) 'Recent climatic trends in 1030 the tropical Atlantic', Climate Dynamics, 43(11), pp. 3071-3089. doi: 10.1007/s00382-014-2168-7.

1031 Siongco, A. C., Hohenegger, C. and Stevens, B. (2015) 'The Atlantic ITCZ bias in CMIP5 models', Climate 1032 Dynamics. Springer Berlin Heidelberg, 45(5-6), pp. 1169-1180. doi: 10.1007/s00382-014-2366-3.

1033 Small, J. R., Curchitser, E., Hedstrom, K., Kauffman, B. and Large, W. G. (2015) 'The Benguela upwelling 1034 system: Quantifying the sensitivity to resolution and coastal wind representation in a global climate model', 1035 Journal of Climate, 28(23), pp. 9409-9432. doi: 10.1175/JCLI-D-15-0192.1.

1036 Smith, S. D. (1980) 'Wind Stress and Heat Flux over the Ocean in Gale Force Winds', Journal of Physical 1037 Oceanography, pp. 709-726. doi: 10.1175/1520-0485(1980)010<0709:WSAHFO>2.0.CO;2. 
Smith, T. M. and Reynolds, R. W. (2003) 'Extended reconstruction of global sea surface temperatures based on COADS data (1854-1997)', Journal of Climate, 16(10), pp. 1495-1510. doi: 10.1175/1520-044216.10.1495.

Sousa, M. C., Alvarez, I., deCastro, M., Gomez-Gesteira, M. and Dias, J. M. (2017) ‘Seasonality of coastal upwelling trends under future warming scenarios along the southern limit of the canary upwelling system', Progress in Oceanography. Elsevier Ltd, 153, pp. 16-23. doi: 10.1016/j.pocean.2017.04.002.

Sousa, M. C., deCastro, M., Alvarez, I., Gomez-Gesteira, M. and Dias, J. M. (2017) 'Why coastal upwelling is expected to increase along the western Iberian Peninsula over the next century?', Science of the Total Environment, 592, pp. 243-251. doi: 10.1016/j.scitotenv.2017.03.046.

Speth, P. (1978) 'Meteorological influence on upwelling off Northwest Africa', Deutsche Hydrographische Zeitschrift, 31(3), pp. 95-104. doi: 10.1007/BF02227007.

Sverdrup, H. (1938) 'On the Process of upwelling', 10(18), pp. 155-164.

Sydeman, W. J., García-Reyes, M., Schoeman, D. S., Rykaczewski, R. R., Thompson, S. A., Black, B. . A. and Bograd, S. J. (2014) 'Climate change and wind intensification in coastal upwelling ecosystems', Science, 345(6192), pp. 77-80. doi: 10.1126/science.1251635.

Taylor, K. E., Stouffer, R. J. and Meehl, G. A. (2012) ‘An overview of CMIP5 and the experiment design', Bulletin of the American Meteorological Society, 93(4), pp. 485-498. doi: 10.1175/BAMS-D-11-00094.1.

Torres, R. (2003) 'Spatial patterns of wind and sea surface temperature in the Galician upwelling region', Journal of Geophysical Research, 108(C4), p. 3130. doi: 10.1029/2002JC001361.Wahl, S., Latif, M., Park, W. and Keenlyside, N. (2011) 'On the Tropical Atlantic SST warm bias in the Kiel Climate Model', Climate Dynamics, 36(5-6), pp. 891-906. doi: 10.1007/s00382-009-0690-9.

Wang, D., Gouhier, T. C., Menge, B. A. and Ganguly, A. R. (2015) 'Intensification and spatial homogenization of coastal upwelling under climate change', Nature, p. 390 . doi: 10.1017/CBO9781107415324.004. 
1062 Xu, Z., Chang, P., Richter, I., Kim, W. and Tang, G. (2014) 'Diagnosing southeast tropical Atlantic SST and 1063 ocean circulation biases in the CMIP5 ensemble', Climate Dynamics, 43(11), pp. 3123-3145. doi: $1064 \quad 10.1007 / \mathrm{s} 00382-014-2247-9$.

1065 Yoon, J. H. and Philander, S. G. H. (1982) 'The generation of coastal undercurrents', Journal of the 1066 Oceanographical Society of Japan, 38(4), pp. 215-224. doi: 10.1007/BF02111104.

1067 Zeeberg, J. J., Corten, A., Tjoe-Awie, P., Coca, J. and Hamady, B. (2008) 'Climate modulates the effects of 1068 Sardinella aurita fisheries off Northwest Africa', Fisheries Research, 89(1), pp. 65-75. doi: $1069 \quad$ 10.1016/j.fishres.2007.08.020

1070 


\begin{tabular}{|c|c|c|c|c|}
\hline \multicolumn{2}{|r|}{ Model } & \multicolumn{2}{|c|}{ Available data } & \multirow{2}{*}{$\begin{array}{l}\text { Depth (in } m \text { ) } \\
\text { used to } \\
\text { compute } U_{w}\end{array}$} \\
\hline & Acronym & Historical & $\mathrm{RCP} 85$ & \\
\hline 1 & ACCESS1-0 & $\begin{array}{c}\text { sst, wind stress, ssh } \\
\text { wmo, psl, pr, uas, vas, }\end{array}$ & $\begin{array}{c}\text { sst, wind stress, ssh } \\
\text { wmo, psl, pr, uas, vas, }\end{array}$ & 49 \\
\hline 2 & ACCESS1-3 & $\begin{array}{l}\text { sst, wind stress, ssh, } \\
\text { wmo, psl, pr, uas, vas }\end{array}$ & $\begin{array}{l}\text { sst, wind stress, ssh, } \\
\text { wmo, psl, pr, uas, vas }\end{array}$ & 54 \\
\hline 3 & bcc-csm1-1 & $\begin{array}{c}\text { sst, wind stress, ssh } \\
\text { wmo, psl, pr, uas, vas }\end{array}$ & $\begin{array}{c}\text { sst, wind stress, ssh } \\
\text { wmo, psl, pr, uas, vas }\end{array}$ & 30 \\
\hline 4 & bcc-csm1-1-m & $\begin{array}{l}\text { sst, wind stress, ssh } \\
\text { wmo, psl, pr, uas, vas }\end{array}$ & $\begin{array}{c}\text { sst, wind stress, ssh } \\
\text { wmo, psl, pr, uas, vas }\end{array}$ & 30 \\
\hline 5 & CanCM4 & $\begin{array}{l}\text { sst, ssh } \\
\text { psl, pr }\end{array}$ & & \\
\hline 6 & CanESM2 & $\begin{array}{l}\text { sst, wind stress, ssh, mld } \\
\text { wmo, psl, pr, uas, vas }\end{array}$ & $\begin{array}{l}\text { sst, wind stress, ssh, mld } \\
\text { wmo, psl, pr, uas, vas }\end{array}$ & 49 \\
\hline 7 & CSIRO-QCCCE & $\begin{array}{l}\text { sst, wind stress, ssh } \\
\text { psl, pr, uas, vas }\end{array}$ & $\begin{array}{l}\text { sst, wind stress, ssh } \\
\text { psl, pr, uas, vas }\end{array}$ & \\
\hline 8 & CNRM-CM5 & $\begin{array}{l}\text { sst, wind stress, ssh, mld wmo, } \\
\text { psl, pr, uas, vas }\end{array}$ & $\begin{array}{l}\text { sst, wind stress, ssh, mld } \\
\text { wmo, psl, pr, uas, vas }\end{array}$ & 44 \\
\hline 9 & CNRM-CM5-2 & $\begin{array}{l}\text { sst, wind stress, ssh, mld wmo, } \\
\text { psl, pr }\end{array}$ & & 40 \\
\hline 10 & CMCC- $\mathrm{CM}$ & $\begin{array}{l}\text { sst, wind stress, ssh } \\
\text { wmo, psl, pr, }\end{array}$ & $\begin{array}{l}\text { sst, wind stress, ssh } \\
\text { wmo, pr }\end{array}$ & 30 \\
\hline 11 & CMCC-CMS & $\begin{array}{c}\text { sst, wind stress, ssh } \\
\text { wmo, psl, pr, uas, vas }\end{array}$ & $\begin{array}{c}\text { sst, wind stress, ssh } \\
\text { wmo, psl, pr, uas, vas }\end{array}$ & 40 \\
\hline 12 & CMCC-CESM & $\begin{array}{c}\text { sst, wind stress, ssh } \\
\text { wmo, psl, pr, uas, vas }\end{array}$ & $\begin{array}{c}\text { sst, wind stress, ssh } \\
\text { wmo, psl, pr, uas, vas }\end{array}$ & 50 \\
\hline 13 & CCSM4 & $\begin{array}{l}\text { sst, wind stress, ssh, mld, wmo, } \\
\text { psl, pr, uas, vas }\end{array}$ & $\begin{array}{c}\text { sst, } \\
\text { wmo, psl, pr, uas, vas }\end{array}$ & 49 \\
\hline 14 & CESM1-CAM5-1- FV2 & sst, wind stress & sst & \\
\hline 15 & CESM1-CAM5 & $\begin{array}{l}\text { sst, wind stress, ssh, mld wmo, } \\
\text { psl, pr, uas, vas }\end{array}$ & $\begin{array}{l}\text { sst, wind stress, ssh, mld } \\
\text { wmo, psl, pr, uas, vas }\end{array}$ & 41 \\
\hline 16 & CESM1-FASTCHEM & $\begin{array}{l}\text { sst, wind stress, ssh, mld wmo, } \\
\text { psl, pr }\end{array}$ & & 49 \\
\hline 17 & CESM1-WACCM & $\begin{array}{l}\text { sst, wind stress, ssh, mld wmo, } \\
\text { psl, pr }\end{array}$ & $\begin{array}{l}\text { sst } \\
\text { pr }\end{array}$ & 42 \\
\hline 18 & CESM1-BGC & $\begin{array}{l}\text { sst, wind stress, ssh, mld wmo, } \\
\text { psl, pr, uas, vas }\end{array}$ & $\begin{array}{l}\text { sst, wind stress, ssh, mld } \\
\text { wmo, psl, pr, uas, vas }\end{array}$ & 51 \\
\hline 19 & EC-EARTH & $\begin{array}{l}\text { sst, wind stress } \\
\text { psl, pr, uas, vas }\end{array}$ & $\begin{array}{l}\text { sst, wind stress } \\
\text { psl, pr, uas, va }\end{array}$ & \\
\hline 20 & FIO-ESM & $\begin{array}{l}\text { sst, wind stress } \\
\text { psl, pr, uas, vas }\end{array}$ & $\begin{array}{l}\text { sst, wind stress } \\
\text { psl, pr, uas, vas }\end{array}$ & \\
\hline 21 & GFDL-CM2p1 & $\begin{array}{l}\text { sst, wind stress, ssh } \\
\text { psl, pr }\end{array}$ & & \\
\hline
\end{tabular}




\begin{tabular}{|c|c|c|c|c|}
\hline 22 & GFDL-CM3 & $\begin{array}{l}\text { sst, wind stress, ssh, mld wmo, } \\
\text { psl, pr, uas, vas }\end{array}$ & $\begin{array}{l}\text { sst, wind stress, ssh, mld } \\
\text { wmo, psl, pr, uas, vas }\end{array}$ & 32 \\
\hline 23 & GFDL-ESM2G & $\begin{array}{l}\text { sst, wind stress, ssh, mld psl, } \\
\text { pr, uas, vas }\end{array}$ & $\begin{array}{l}\text { sst, wind stress, ssh, mld psl, } \\
\text { pr, uas, vas }\end{array}$ & \\
\hline 24 & GFDL-ESM2M & $\begin{array}{l}\text { sst, wind stress, ssh, mld wmo, } \\
\text { psl, pr, uas, vas }\end{array}$ & $\begin{array}{l}\text { sst, wind stress, ssh, mld } \\
\text { wmo, psl, pr, uas, vas }\end{array}$ & 37 \\
\hline 25 & GISS-E2-H-CC & $\begin{array}{c}\text { sst } \\
\text { psl, pr, uas, vas }\end{array}$ & $\begin{array}{c}\text { sst } \\
\text { psl, pr, uas, vas }\end{array}$ & \\
\hline 26 & GISS-E2-R-CC & $\begin{array}{c}\text { sst, ssh } \\
\text { wmo, psl, pr, uas, vas }\end{array}$ & $\begin{array}{c}\text { sst, ssh } \\
\text { wmo, psl, pr, uas, vas }\end{array}$ & 30 \\
\hline 27 & GISS-E2-H & $\begin{array}{c}\text { sst } \\
\text { psl, pr, uas, vas }\end{array}$ & $\begin{array}{c}\text { sst } \\
\text { psl, pr, uas, vas }\end{array}$ & \\
\hline 28 & GISS-E2-R & $\begin{array}{c}\text { sst, ssh } \\
\text { wmo, psl, pr, uas, vas }\end{array}$ & $\begin{array}{c}\text { sst, ssh } \\
\text { wmo, psl, pr, uas, vas }\end{array}$ & 30 \\
\hline 29 & HadCM3 & $\begin{array}{c}\text { sst } \\
\text { psl, pr, uas, vas }\end{array}$ & & \\
\hline 30 & HadGEM2-CC & $\begin{array}{c}\text { sst } \\
\text { psl, pr, uas, vas }\end{array}$ & $\begin{array}{c}\text { sst } \\
\text { psl, pr, uas, vas }\end{array}$ & 40 \\
\hline 31 & HadGEM2-ES & $\begin{array}{c}\text { sst } \\
\text { psl, pr, uas, vas }\end{array}$ & $\begin{array}{c}\text { sst } \\
\text { psl, pr, uas, vas }\end{array}$ & 40 \\
\hline 32 & HadGEM2-AO & $\begin{array}{l}\text { sst, wind stress } \\
\text { psl, pr, uas, vas }\end{array}$ & $\begin{array}{l}\text { sst, wind stress } \\
\text { psl, pr, uas, vas }\end{array}$ & \\
\hline 33 & IPSL-CM5A-LR & $\begin{array}{l}\text { sst, wind stress, ssh, mld wmo, } \\
\text { psl, pr, uas, vas }\end{array}$ & $\begin{array}{l}\text { sst, wind stress, ssh, mld } \\
\text { wmo, psl, pr, uas, vas }\end{array}$ & 49 \\
\hline 34 & IPSL-CM5A-MR & $\begin{array}{l}\text { sst, wind stress, ssh, mld wmo, } \\
\text { psl, pr, uas, vas }\end{array}$ & $\begin{array}{l}\text { sst, wind stress, ssh, mld } \\
\text { wmo, psl, pr, uas, vas }\end{array}$ & 36 \\
\hline 35 & IPSL-CM5B-LR & $\begin{array}{l}\text { sst, wind stress, ssh, mld wmo, } \\
\text { psl, pr, uas, vas }\end{array}$ & $\begin{array}{l}\text { sst, wind stress, ssh, mld } \\
\text { wmo, psl, pr, uas, vas }\end{array}$ & 56 \\
\hline 36 & INM & $\begin{array}{l}\text { sst, wind stress, ssh, } \\
\text { wmo, psl, pr, uas, vas }\end{array}$ & $\begin{array}{l}\text { sst, wind stress, ssh, } \\
\text { wmo, psl, pr, uas, vas }\end{array}$ & \\
\hline 37 & LASG-IAP & $\begin{array}{l}\text { sst, wind stress, ssh, } \\
\text { wmo, psl, pr, uas, vas }\end{array}$ & $\begin{array}{l}\text { sst, wind stress, ssh, } \\
\text { wmo, psl, pr, uas, vas }\end{array}$ & 50 \\
\hline 38 & LASG-CESS & $\begin{array}{l}\text { sst, ssh } \\
\text { psl, pr }\end{array}$ & & \\
\hline 39 & MRI-CGCM3 & $\begin{array}{l}\text { sst, wind stress, ssh, mld wmo, } \\
\text { psl, pr, uas, vas }\end{array}$ & $\begin{array}{l}\text { sst, wind stress, ssh, mld } \\
\text { wmo, psl, pr, uas, vas }\end{array}$ & 54 \\
\hline 40 & MRI-ESM1 & $\begin{array}{l}\text { st, wind stress, ssh, mld wmo, } \\
\text { psl, pr, uas, vas }\end{array}$ & $\begin{array}{l}\text { st, wind stress, ssh, mld } \\
\text { wmo, psl, pr, uas, vas }\end{array}$ & 56 \\
\hline 41 & MIROC-ESM & $\begin{array}{l}\text { sst, wind stress, ssh } \\
\text { psl, pr, uas, vas }\end{array}$ & $\begin{array}{l}\text { sst, wind stress, ssh } \\
\text { psl, pr, uas, vas }\end{array}$ & \\
\hline 42 & MIROC5 & $\begin{array}{l}\text { sst, wind stress, ssh } \\
\text { wmo, psl, pr, uas, vas }\end{array}$ & $\begin{array}{c}\text { sst, wind stress, ssh } \\
\text { wmo, psl, pr, uas, vas }\end{array}$ & 50 \\
\hline 43 & MPI-ESM-LR & $\begin{array}{l}\text { sst, wind stress, ssh, mld wmo, } \\
\text { psl, pr, uas, vas }\end{array}$ & $\begin{array}{l}\text { sst, wind stress, ssh, mld } \\
\text { wmo, psl, pr, uas, vas }\end{array}$ & 39 \\
\hline 44 & MPI-ESM-MR & $\begin{array}{l}\text { sst, wind stress, ssh, mld wmo, } \\
\text { psl, pr, uas, vas }\end{array}$ & $\begin{array}{l}\text { sst, wind stress, ssh, mld } \\
\text { wmo, psl, pr, uas, vas }\end{array}$ & 39 \\
\hline
\end{tabular}




\begin{tabular}{|c|c|c|c|c|}
\hline 45 & MPI-ESM-P & $\begin{array}{l}\text { sst, wind stress, ssh, mld wmo, } \\
\text { psl, pr }\end{array}$ & & 39 \\
\hline 46 & NorESM1-ME & $\begin{array}{l}\text { sst, wind stress, ssh, mld wmo, } \\
\text { psl, pr, uas, vas }\end{array}$ & $\begin{array}{l}\text { sst, wind stress, ssh, mld } \\
\text { wmo, psl, pr, uas, vas }\end{array}$ & 69 \\
\hline 47 & NorESM1- M & $\begin{array}{l}\text { ssst, wind stress, ssh,mld wmo, } \\
\text { psl, pr, uas, vas }\end{array}$ & $\begin{array}{l}\text { ssst, wind stress, ssh,mld } \\
\text { wmo, psl, pr, uas, vas }\end{array}$ & 70 \\
\hline
\end{tabular}

Table1: List of the CMIP5 simulations used in this study. The third and fourth columns list the variables that were available for our study: surface temperature (sst), wind stress, sea surface heigh (ssh, called zos in the CMIP5 database), mixed layer depth (mld, omlmax in the CMIP5 database), sea level pressure (slp), precipitation (pr), zonal and meridional surface wind components (uas and vas) and upward ocean mass transport (wmo). This latter variable (given in $\mathrm{kg} . \mathrm{s}^{-1}$ in the CMIP5 outputs) has been systematically converted into vertical velocity (in m.s-1). For this conversion, we have used the average density of sea water in the region of the study $\left[12^{\circ} \mathrm{N}-20^{\circ} \mathrm{N} 6^{\circ} \mathrm{W}-20^{\circ} \mathrm{W}\right]$ estimated from the SODA reanalysis (Carton and Giese 2008). The last column indicate the depth which compute the direct estimation of the total upwelling transport (see Appendix B for details). 

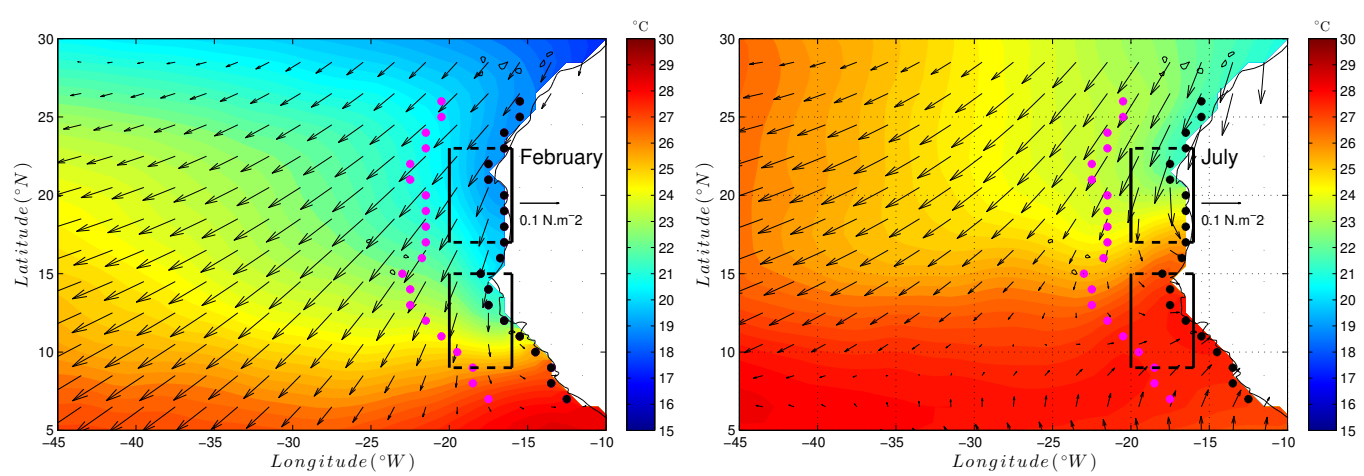

Figure 1: Colors: SST (HadISST) climatological mean (in ${ }^{\circ} C$ ) in February (left) and July (right) averaged over the period [1985-2005]. Vectors: Tropflux climatological wind stress for the same months respectively and the same period. The solid dots indicate the coastal (black) and offshore (magenta) locations used for the computation of the $U I_{s s t}^{\text {cross }}$ (see section 3.1.b). The black and magenta dots are separated by $5^{\circ}$ of longitude. The black boxes represent the regions used for the computation of the SSH meridional gradient ( section 3.3). 


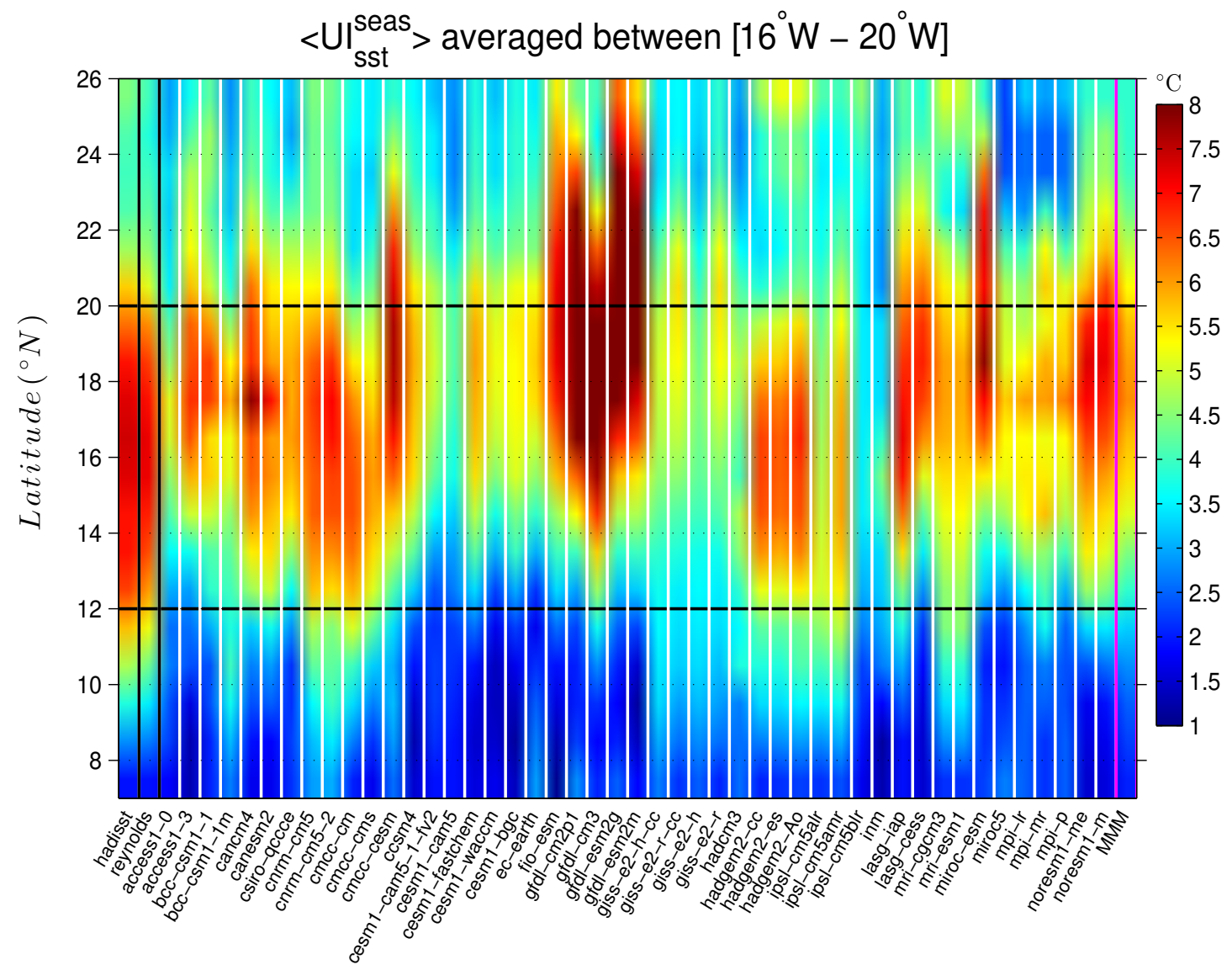

Figure 2: <UI sst $>$ averaged zonally between $16^{\circ} \mathrm{W}$ and $20^{\circ} \mathrm{W}$ and shown as a function of latitude. The first two columns on the left (highlighted in black) show the observation data sets (HadISST and Reynolds respectively). The other bands show the individual CMIP5 models and the last column (highlighted in magenta) shows the Multi-Model Mean (MMM). The horizontal dashed lines are positioned at $12^{\circ} \mathrm{N}$ and $20^{\circ} \mathrm{N}$ and give a rough limitation of the senegalo-mauritanian upwelling region in the observations. 
(a) $\left\langle\mathrm{UI}_{\text {sst }}^{\text {cross }}>n\right.$

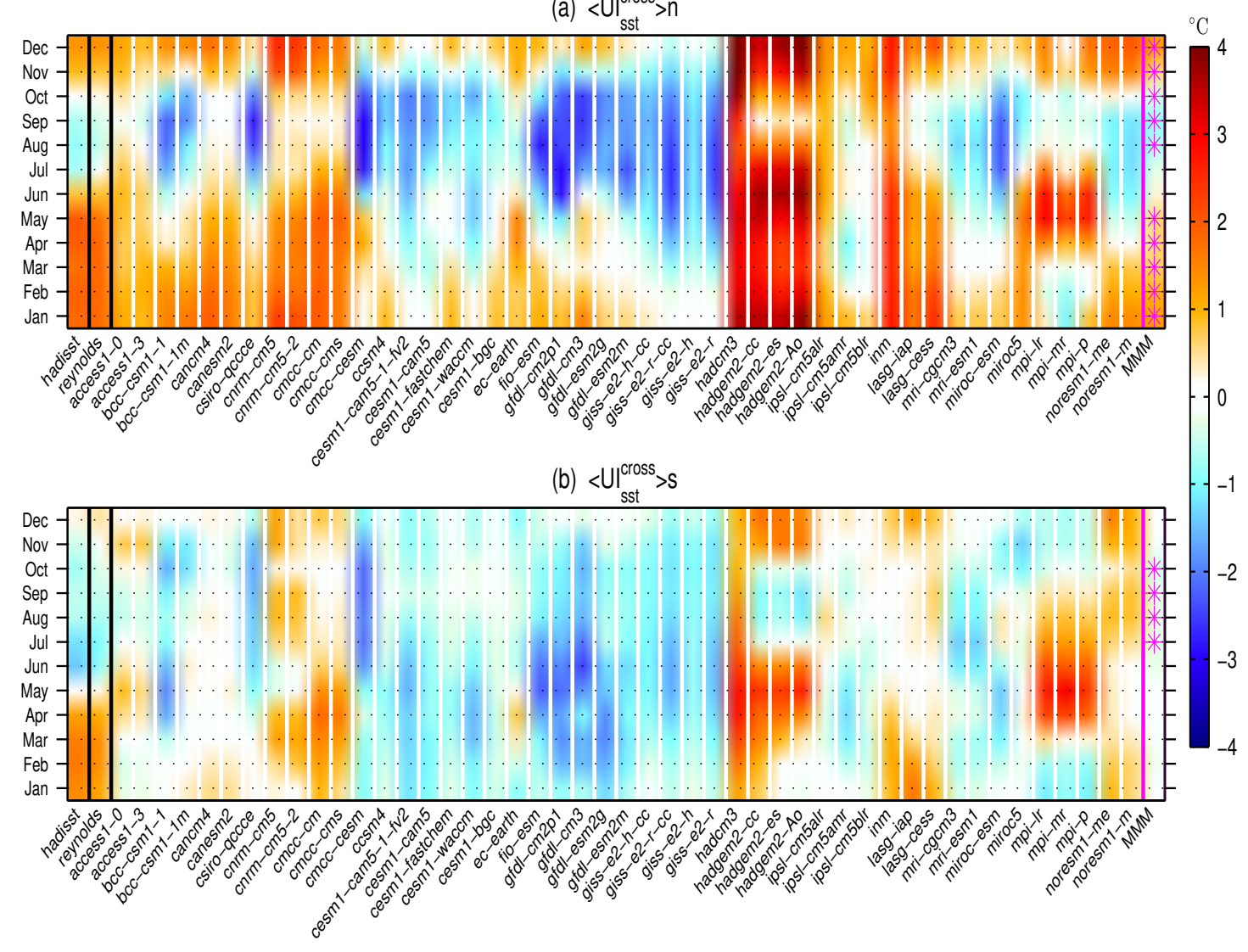

Figure 3: Panel a: monthly climatology [1985-2005] of $U I_{s s t}^{\text {cross }}$, averaged over the northern part of the senegalo-mauritanian area (nSMUS, $\left.\left[16^{\circ} N-20^{\circ} N\right]\right)$, called $<U I_{s s t}^{\text {cross }}>n$. Panel b: same as panel a for the southern zone (sSMUS, $\left.\left[12^{\circ} N-15^{\circ} N\right]\right),<U I_{s s t}^{\text {cross }}>s$. The first two columns on the left (highlighted in black) show the results for the two observational data sets, the other columns show the individual CMIP5 models and the last column in the right, highlighted in magenta, shows the Multi-Model Mean (MMM). Positive (negative) values correspond to upwelling (downwelling) conditions. The magenta stars in the last column mark the months for which the MMM is significant at the $95 \%$ level with respect to the multimodel spread. 


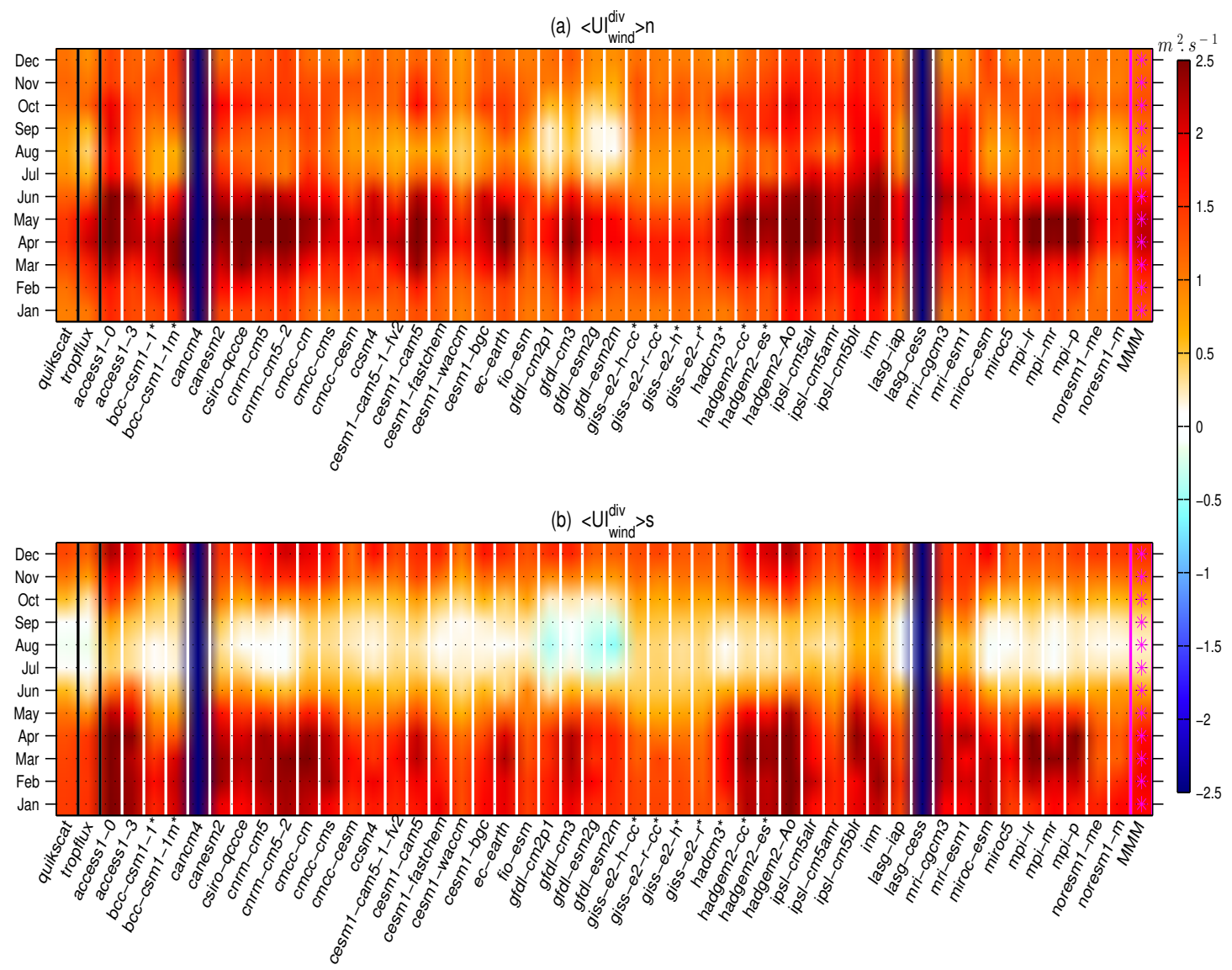

Figure 4: Monthly climatology of $\left\langle U I_{\text {wind }}^{\text {div }}>\right.$ averaged over the northern part $\left[16^{\circ} N-20^{\circ} N\right]$ (panel a, $<U I_{\text {wind }}^{\text {div }}>n$ ) and the southern part $\left[12^{\circ} N-15^{\circ} N\right]$ (panel b, $<U I_{\text {wind }}^{\text {div }}>s$ ) of the senegalo-mauritanian upwelling region and computed over [1985-2005]. On both panels, the first two columns on the left (highlighted in black) show the index in the two validation data sets. The other columns show the individual CMIP5 simulations and the last column in the right (in magenta) shows the multi-model mean (MMM). Positive (negative) values correspond to upwelling (downwelling) conditions. The two dark blue columns stand for models for which neither the near surface wind intensity nor the wind stress was available (CanCM4 and LASG-CESS). The simulations for which the oceanic wind stress was not given directly in the CMIP5 data base and was thus computed offline following the methodology described in Appendix A are marked by a star following their name. See Fig. 3 for comments on the magenta stars 


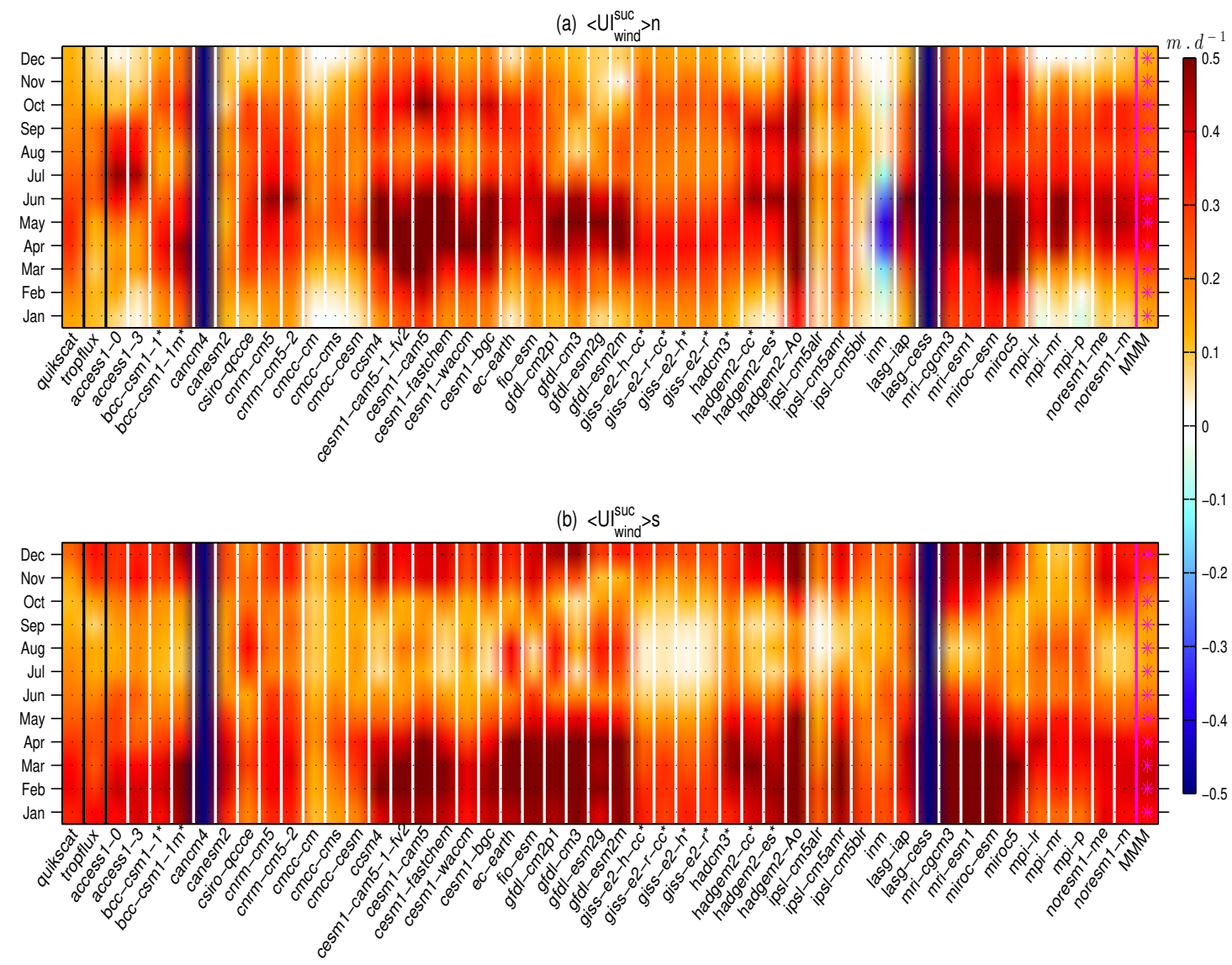

Figure 5: Monthly climatology of the Ekman suction index $\left\langle U I_{\text {wind }}^{\text {suc }}>\right.$ averaged between $\left[16^{\circ} W-20^{\circ} W\right]$ and over the northern part $\left[16^{\circ} N-20^{\circ} N\right]$ (panel a, $<U I_{\text {wind }}^{\text {suc }}>n$ ) and the southern part $\left[12^{\circ} N-15^{\circ} N\right]$ (panel b ,$<U I_{\text {wind }}^{\text {suc }}>s$ ) of the senegalo-mauritanian upwelling. The first two columns on the left (highlighted in black) show the two observational data sets, the other columns show the individual CMIP5 simulations and the last column in the right (in magenta) shows the (MMM) computed over [1985-2005]. The dark blue columns stand for the models which did not provide any wind data (CanCM4 and LASG-CESS). See Fig. 3 for comments on the magenta stars. 


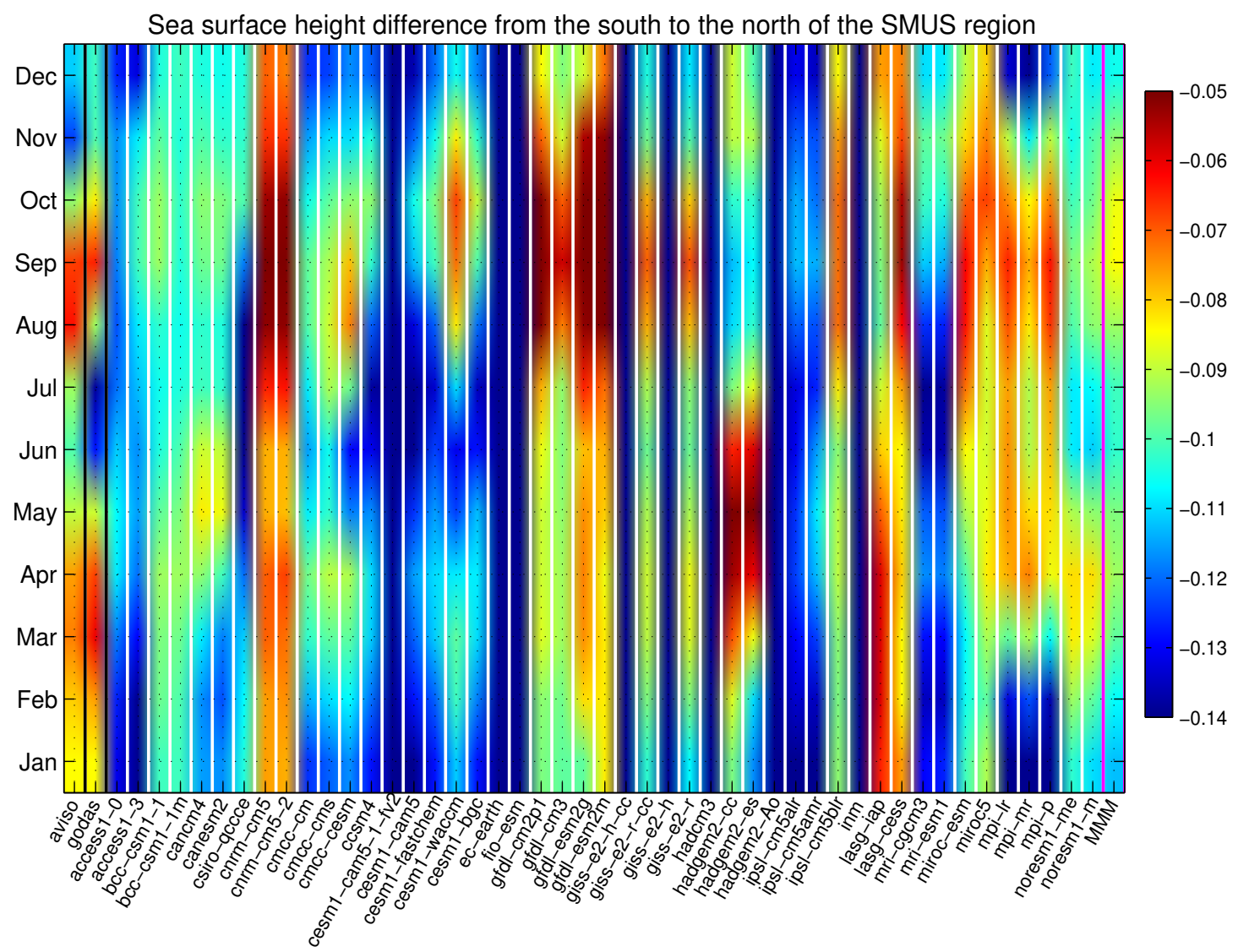

Figure 6: Monthly climatology of the meridional sea surface height difference (units: $m$ ) between the region $\left[9^{\circ} \mathrm{N}-15^{\circ} \mathrm{N} / 16^{\circ} \mathrm{W}-20^{\circ} \mathrm{W}\right]$ and the region $\left[17^{\circ} \mathrm{N}-23^{\circ} \mathrm{N} / 16^{\circ} \mathrm{W}-20^{\circ} \mathrm{W}\right]$. These regions are highlighted in Fig. 1 (black boxes). The first column on the left shows results from AVISO satellite data (period [1993-2005]), and the second one from the GODAS reanalysis [1985-2005]. The following columns show the results of the climate simulations for the period [1985-2005]. The last column on the right (highlighted in magenta) shows the (MMM). The dark blue columns stand for the simulations which did not provide the SSH data (CESM1-Cam5-1-fv2, EC-EARTH, FIO-ESM, GISS-E2-H-CC, GISS-E2-H, HadCM3, HadGem2-AO). 

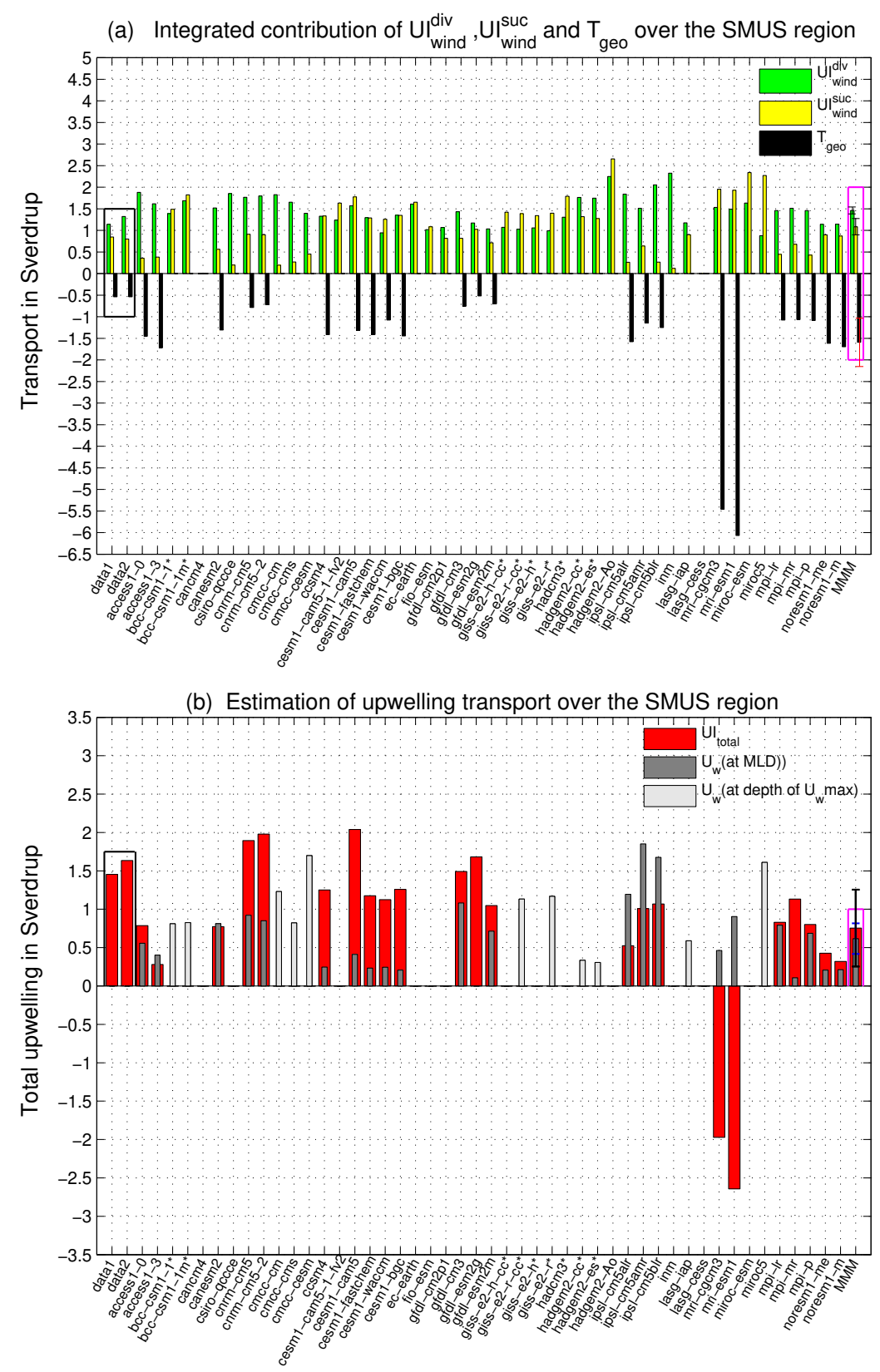

Figure 7: Panel (a): Estimate of the seasonal (November-May) integrated contribution (in Sverdrup) of the three dynamical indices $\left(U I_{\text {wind }}^{\text {div }}, U I_{\text {wind }}^{\text {suc }}\right.$ and $T_{\text {geo }}$ ) to the upwelling. $U I_{\text {wind }}^{\text {suc }}$ (yellow bars) was integrated between $\left[12^{\circ} \mathrm{N}-20^{\circ} \mathrm{N}\right]$ and $\left.\left[16^{\circ} \mathrm{W}-20^{\circ} \mathrm{W}\right]\right), U I_{\text {wind }}^{\text {div }}$ (green bars) was integrated over the same latitude range. $T_{\text {geo }}$ (black bars) was computed from Eq. (5) (see text). Data1 correspond to $U I_{\text {wind }}^{\text {suc }}$ and $U I_{\text {wind }}^{\text {div }}$ computed from Quikscat (2000-2009) and $T_{\text {geo }}$ computed with the AVISO SSH product (1993-2005) and MLD from de Boyer Montegut. Data 2 represent $U I_{\text {wind }}^{\text {suc }}$ and $U I_{\text {wind }}^{\text {div }}$ computed from Tropflux (1985-2005), SSH computed from the GODAS reanalysis (1985-2005) and the same MLD used in data1. The following columns show the results for the individual climate simulations, and the last column (magenta) shows the MMM with confidence interval estimated from a student test of the mean given the dispersion of the individual models. Panel (b): $U I_{\text {total }}$ (red bars) shows an estimation of the total volume of upwelling water computed as the sum of the three contributions shown in panel (a). Data 1 and data 2 are the same as in panel (a). The dark grey bars display the volume of water effectively upwelled in the climate simulations computed as the integral of the vertical velocity diagnosed online over the upwelling region $\left[12^{\circ} N-20^{\circ} N\right] /\left[16^{\circ} \mathrm{W}-20^{\circ} \mathrm{W}\right]$ and taken at MLD. The light grey bars represent the models for $U_{w}$ was taken at the depth maximizing this quantity. The MMM is computed only for the simulations where both $U I_{\text {total }}$ and $U_{w}$ computed at MLD are available. See text for details. 


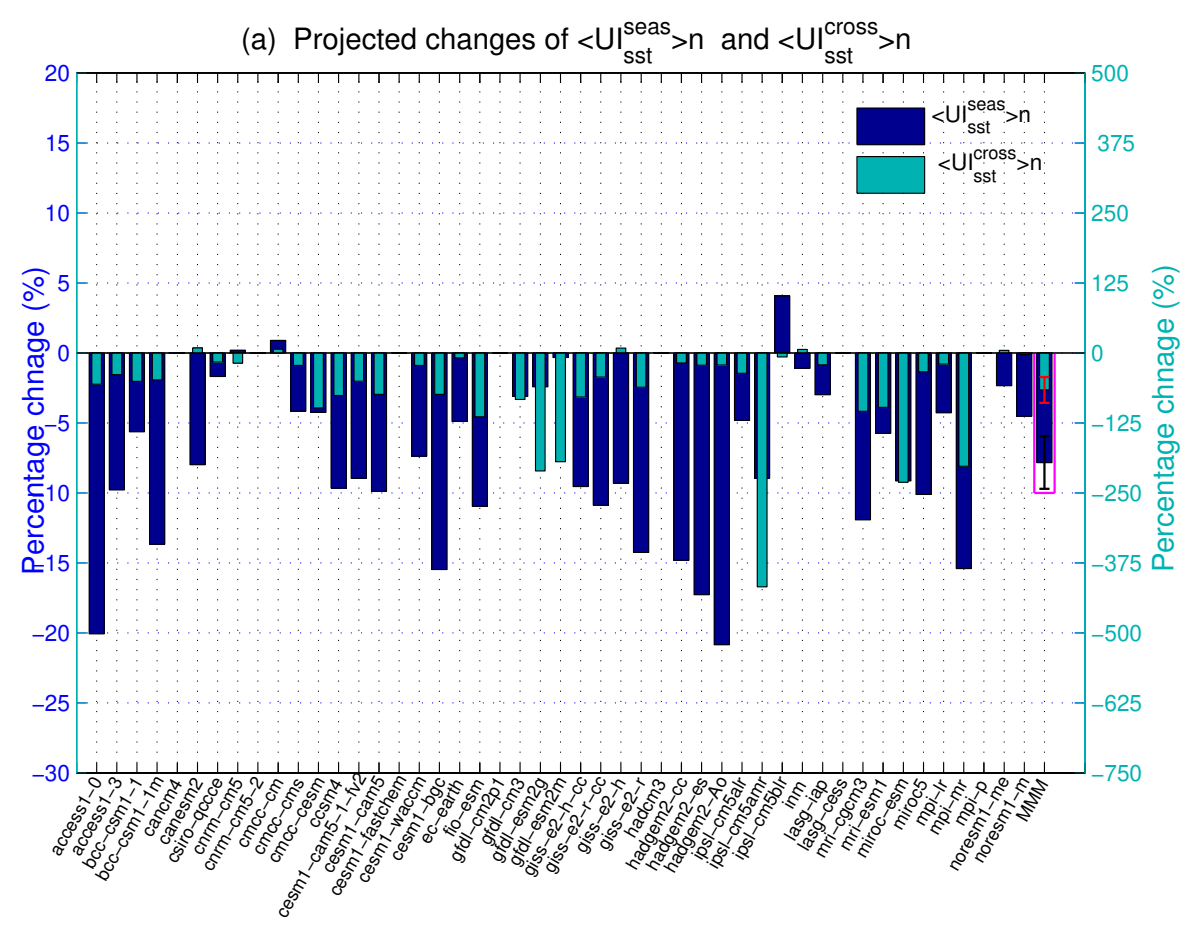

(b) Projected changes of $<\mathrm{UI}_{\mathrm{sst}}^{\mathrm{seas}}>\mathrm{S}$ and $<\mathrm{Ul}_{\mathrm{sst}}^{\text {cross }}>\mathrm{S}$

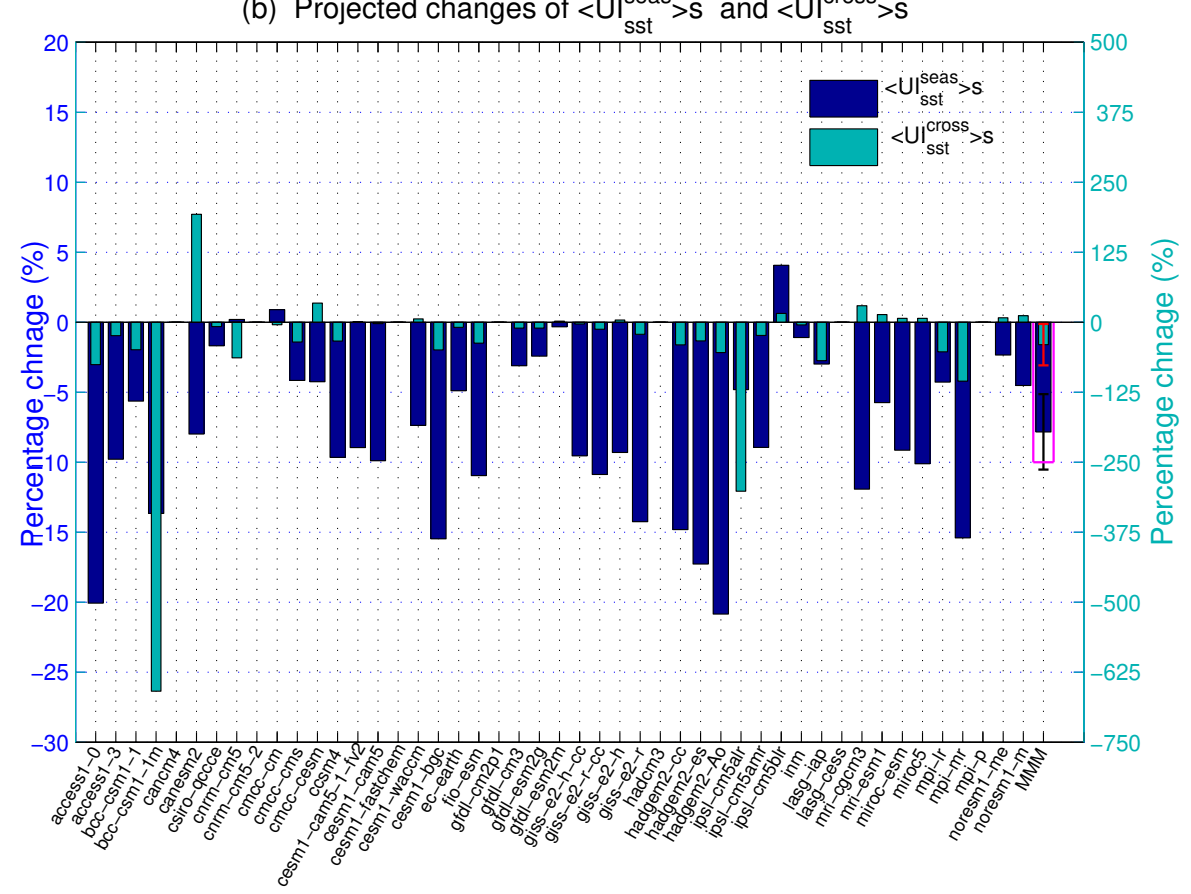

Figure 8: Projected changes of the indices of upwelling thermal signatures averaged over the northern region $\left[16^{\circ} N-20^{\circ} N\right]$ (top panel) and over the southern region $\left[12^{\circ} N-15^{\circ} N\right]$ (bottom panel). The dark blue bars show the projected changes (in \%) of $\left\langle U I_{s s t}^{\text {seas }}>n\right.$. The changes are estimated as the difference between the future [2080-2100] and the historical [1985-2005] period and the percentage is estimated with respect to the historical value. The light blue bars show the projected changes of $\left\langle U I_{s s t}^{\text {cross }}>n\right.$ averaged over the upwelling season (November - May). Models for which SST data was not available for the RCP8.5 scenario are marked by a empty space. The right column (in magenta) shows the percentage of change of the multi-model mean. The black and red whiskers bars indicate the $95 \%$ confidence interval of $\left\langle U I_{\text {sst }}^{\text {seas }}>\right.$ and $<U I_{\text {sst }}^{\text {cross }}>$ MMM respectively. 

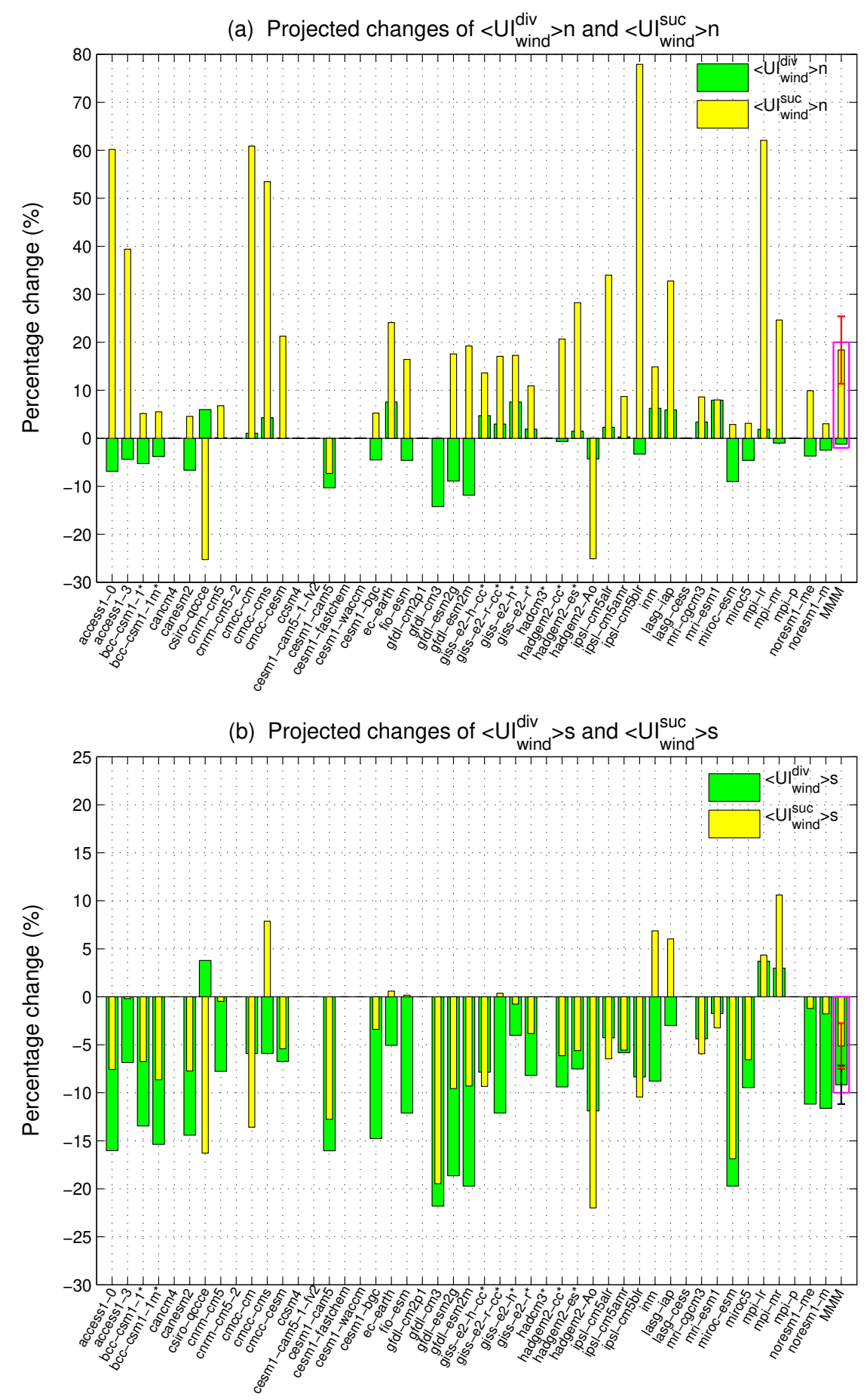

Figure 9: Projected changes of the dynamical indices of the upwelling integrated over the northern region $\left[16^{\circ} N-20^{\circ} N\right]$ (panel (a)) and over the southern region $\left[12^{\circ} N-15^{\circ} N\right]$ (panel (b)). The changes are estimated as the difference between the future [2080-2100] and the historical [1985-2005] period and the percentage is estimated with respect to the historical value. The green bars show the projected changes (in \%) of $<U I_{w i n d}^{d i v}>n$ averaged over the upwelling season (November-May). The yellow bars show the projected changes of $\left\langle U I_{\text {wind }}^{\text {suc }}>n\right.$ integrated over the longitude range $\left[16^{\circ} \mathrm{W}-20^{\circ} \mathrm{W}\right]$ and for the same climatological season. Models for which wind data was not available for the RCP8.5 scenario are marked by a empty space. The right column (in magenta) shows the percentage change of the multi-model mean. The black and red whiskers bars indicate the $95 \%$ confidence interval of $\left\langle U I_{\text {wind }}^{\text {div }}>n\right.$ and $\left\langle U I_{\text {wind }}^{\text {suc }}>n\right.$ respectively. Negative (positive) values exhibit a decrease (increase) of these upwelling indices. 


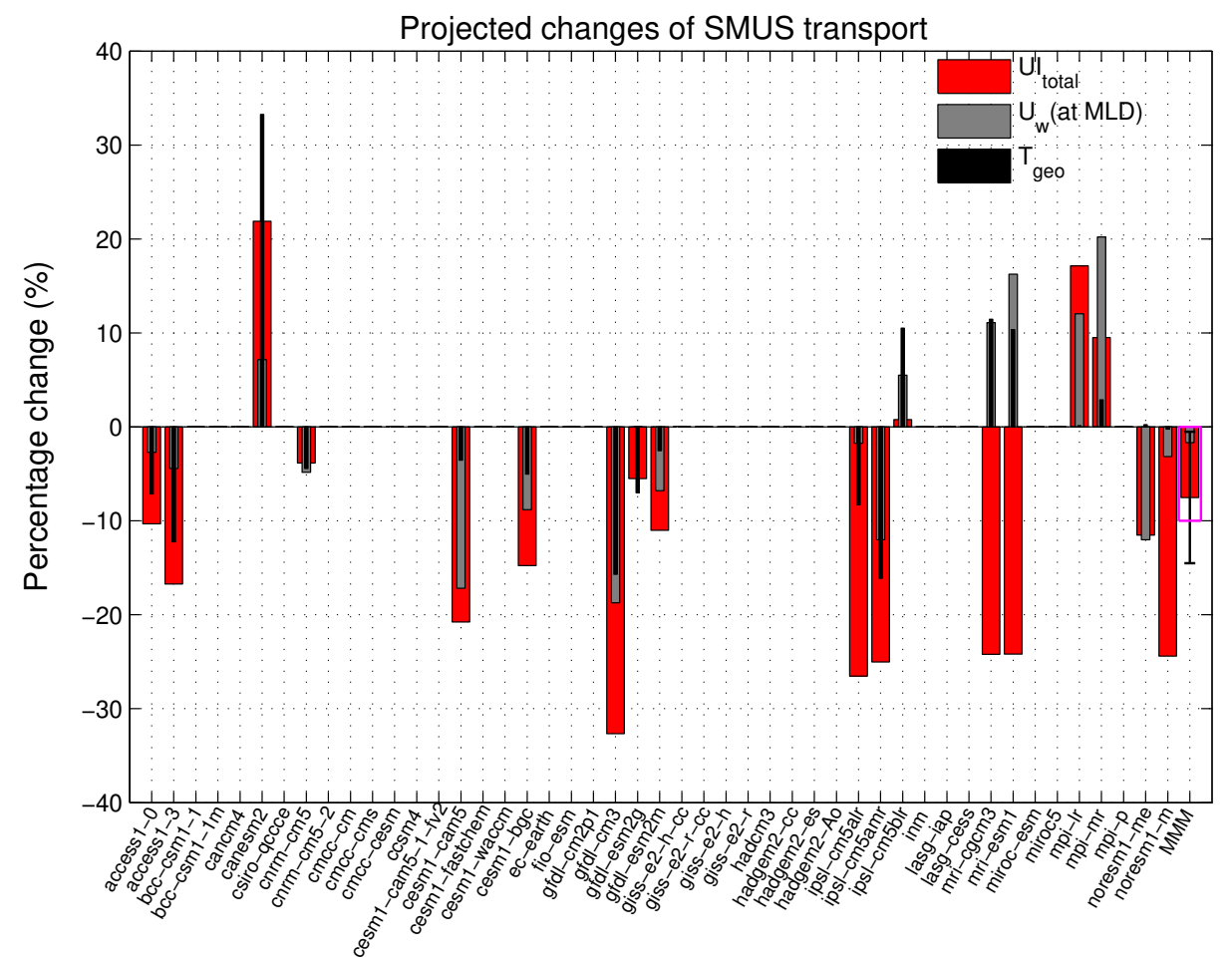

Figure 10: Projected change (in \%) of geostrophic flux $T_{\text {geo }}$, the direct $\left(U_{w}\right)$ and indirect $\left(U I_{\text {total }}\right)$ estimates of the total upwelling of water derived in Fig.7b and for models for which data was available. Here, in particular, we only consider models for which MLD was available both over the historical and the future period. As in Fig.9, the changes are computed as the difference between the future [2080-2100] and the historical [1985-2005] period, and the flux is averaged over the upwelling season (November-May). The grey and red bars show the projected changes of $U_{w}$ (taken at MLD) and $U I_{\text {total }}$ estimates of the total volume of the upwelling respectively. The black bars show the projected change of the volume of upwelling water due to the geostrophic flux $T_{\text {geo }}$. The black whisker bar indicate the $95 \%$ confidence interval of $U I_{\text {total }}$ MMM. 
(a) $\mathrm{MMM}_{\text {Hist }}$

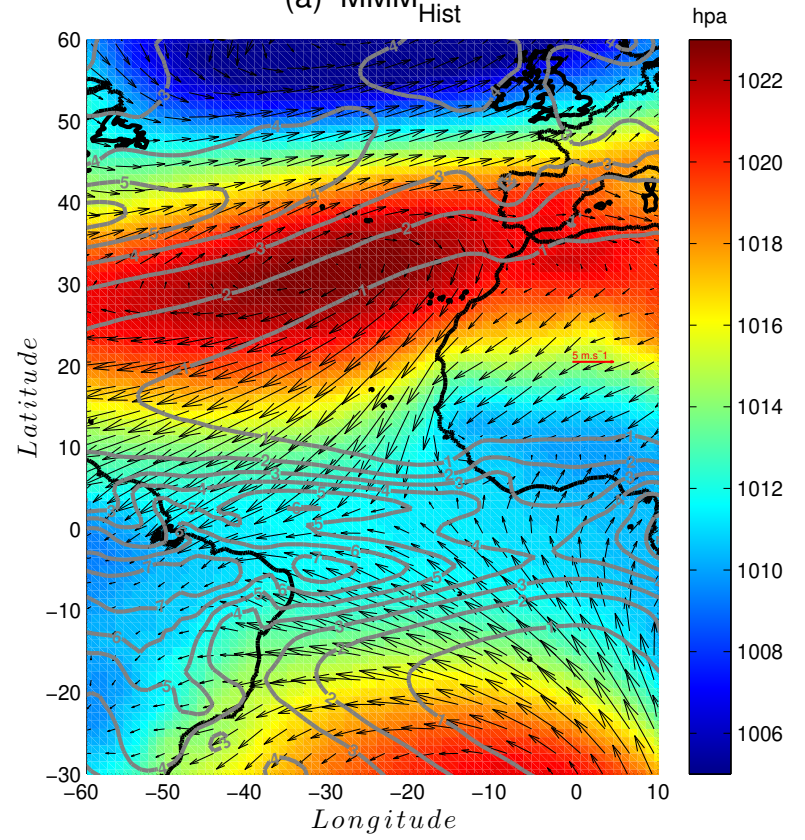

(b) $\mathrm{MMM}_{\text {Fut }}-\mathrm{MMM}_{\text {Hist }}$

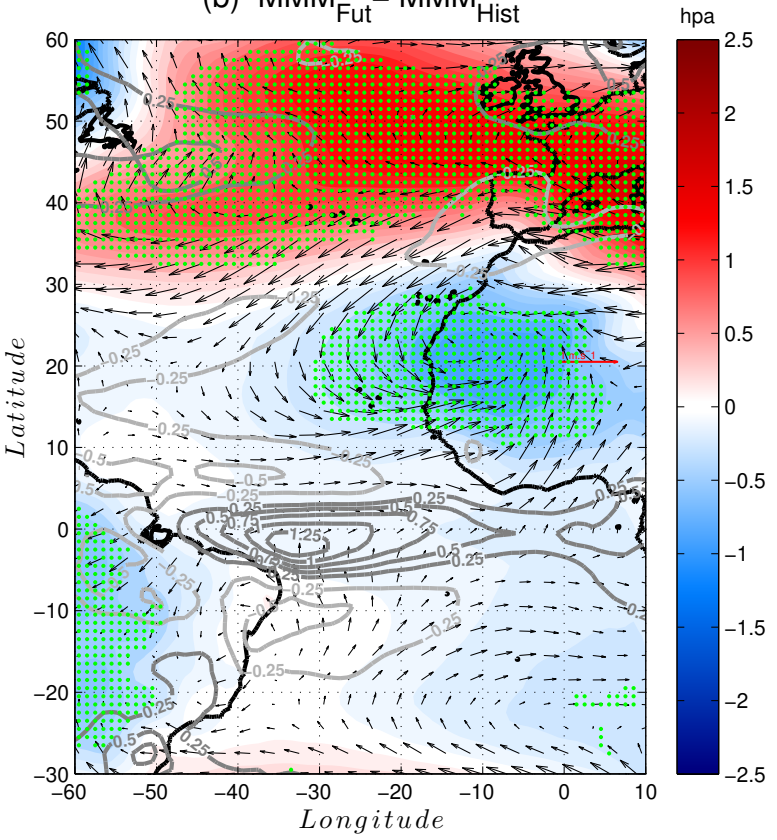

Figure 11: Panel (a): Climatology of sea level pressure (color), surface winds (vectors) and precipitation (contours) in the (MMM) averaged from November to May over the historical period [1985-2005]. Panel (b) shows the projected changes of these atmospherics variables. Regions where more than $75 \%$ models agree on the sign of the changes are indicated with green dots. These figures are computed from the 37 simulations which have at the same time the sea level pressure, precipitation and surface wind over both periods. 
(a) Position of the Azores Anticyclone

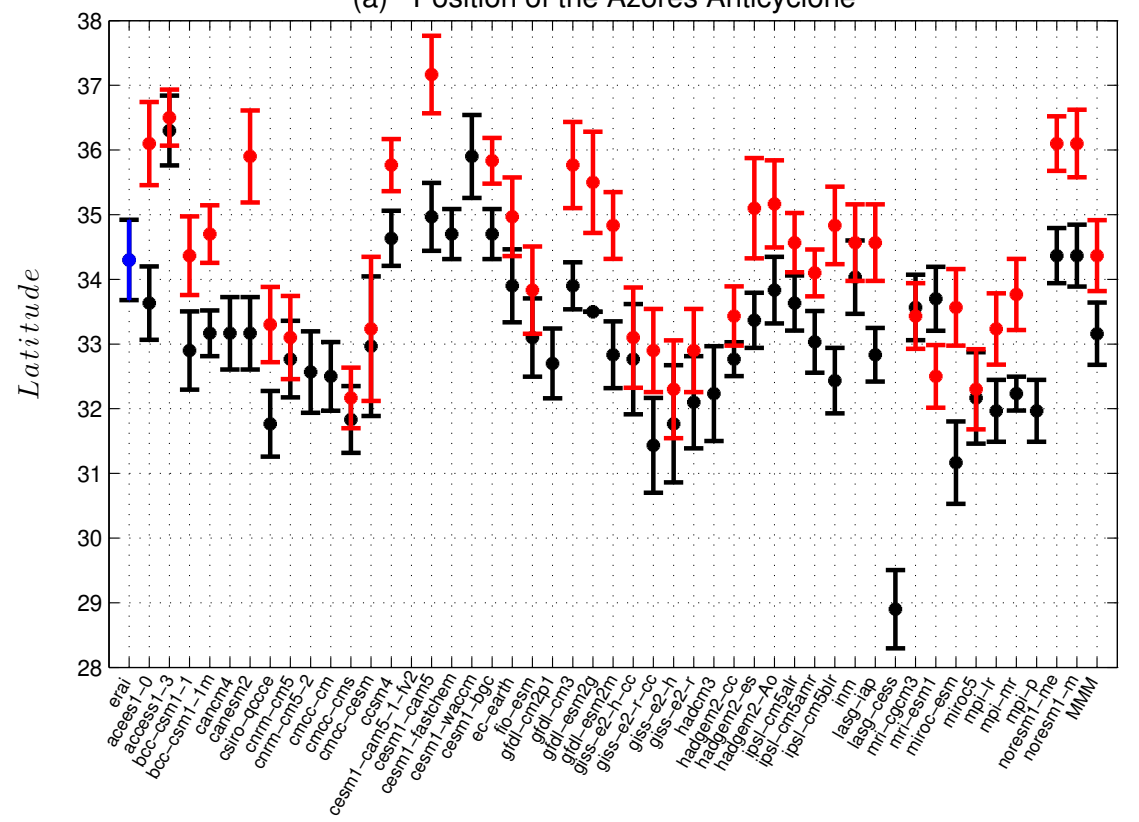

(b) Position of ITCZ

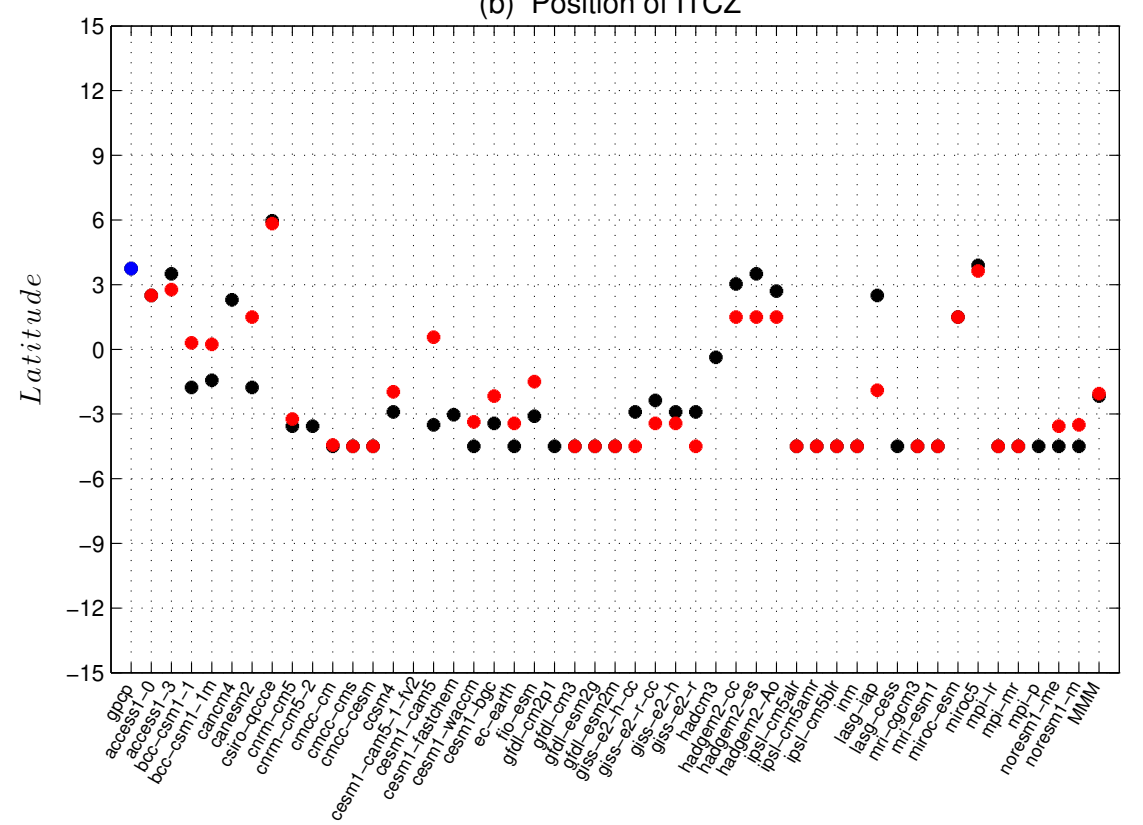

Figure 12: Panel (a): Comparison of the latitudinal position of the Azores Anticyclone over the historical ([1985-2005], black for models and blue for ERAI) and the future ([2080-2100], red) period for the November-May season. The latitude of the SLP maximum is diagnosed for each longitude between $15^{\circ} \mathrm{W}$ and $30^{\circ} \mathrm{W}$ (21 grid points). The whiskers show the average of these 21 latitudes and the $5-95 \%$ uncertainty range. Panel (b): Comparison of the latitudinal position of the ITCZ over the historical ([1985-2005], black for models and blue for GPCP) and the future ([2080-2100], red) period for the November-May season. This position is estimated as the latitude of the precipitation maximum over the same longitude range as above. We found a very small dependency of the latitude in longitude, so that no uncertainty range could be given here. 